\title{
Apparent wall slip effects on rheometric measurements of waxy gels
}

Thiago O. Marinho, Flávio H. Marchesini, Márcia C. K. de Oliveira, and Márcio Nele

Citation: Journal of Rheology 65, 257 (2021); doi: 10.1122/8.0000111

View online: https://doi.org/10.1122/8.0000111

View Table of Contents: https://sor.scitation.org/toc/jor/65/2

Published by the The Society of Rheology

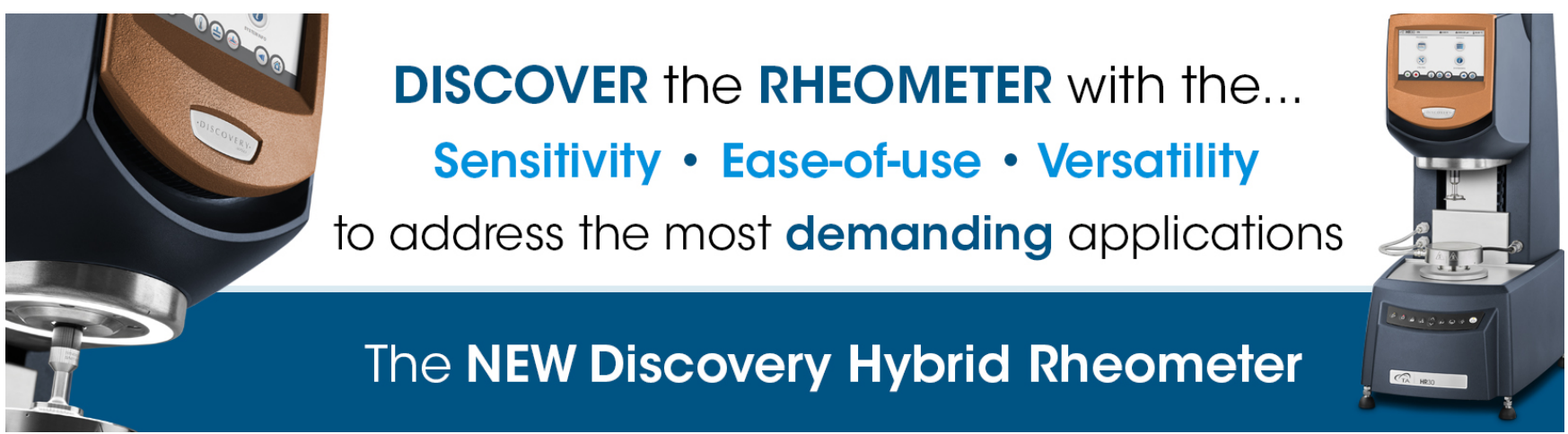




\title{
Apparent wall slip effects on rheometric measurements of waxy gels
}

\author{
Thiago O. Marinho, ${ }^{1}$ Flávio H. Marchesini, ${ }^{2}$ Márcia C. K. de Oliveira, ${ }^{3}$ and Márcio Nele ${ }^{1, a)}$ \\ ${ }^{1}$ Chemical Engineering Program/COPPE, Federal University of Rio de Janeiro (UFRJ), Rio de Janeiro 21941-972, \\ Brazil \\ ${ }^{2}$ Centre for Polymer and Material Technologies, Department of Materials, Textiles and Chemical Engineering, Ghent \\ University, 9052 Zwijnaarde, Belgium \\ ${ }^{3}$ Petrobras, Research Center Leopoldo Américo Miguez de Mello (CENPES), University City, Rio de Janeiro 21941 -
} 970, Brazil

(Received 23 June 2020; final revision received 1 February 2021; published 25 February 2021)

\begin{abstract}
The effects of apparent wall slip on rheometric measurements of waxy gels are quantified for gels consisting of a macrocrystalline wax added in mineral oil in concentrations of 3.0 and $7.5 \mathrm{wt}$. \%. The waxy gels are formed in situ in a stress-controlled rheometer, and rheological properties are then obtained. Seven different geometry configurations, including parallel plates, concentric cylinders, and vane, are employed. The surface roughness of the different geometries and wax crystals size are assessed to provide insight into the apparent wall slip phenomenon. In the presence of smooth surfaces, a decrease in approximately $80 \%$ in the measured yield stress value is observed in oscillatory tests, regardless of system composition. In addition, the storage modulus measurements are substantially different when obtained from smooth or grooved geometries. In creep experiments, the yield stress measurements decrease by $68 \%$. As expected, apparent wall slip markedly affects the shape of the flow curves obtained, causing the appearance of kinks for smooth Couette geometry. Apparent slip velocities are calculated in the regime just above the yield stress, and it is found that for low concentrations apparent slip increases with concentration and decreases with the ratio between the shear stress and dynamic yield stress. The gathered results also demonstrate that the reproducibility of rheological measurements is improved by using geometries with grooved parts. By quantifying the effects of apparent wall slip on rheological measurements of waxy gels for different geometries, this work can provide useful information for the design of pipelines and oil transportation processes. (C) 2021 The Society of Rheology. https://doi.org/10.1122/8.0000111
\end{abstract}

\section{INTRODUCTION}

Waxy gels can be formed upon the cooling of oils containing waxy compounds because of precipitation of wax crystals at sufficiently low temperatures [1,2]. This subject is particularly relevant to the petroleum industry, as severe issues can arise in the field during crude oil production and transportation in cold environments, such as deepwater and arctic regions [3-7]. In these scenarios, crude oils can undergo a gelation process, and the pipelines can become clogged with waxy gels [1-6]. These gels present a complex rheological behavior that needs to be accurately measured for the proper design of transport processes involving these materials [8-12]. In particular, the yield stress of a waxy gel is a critical property, as it effectively determines the pump capacity required to initiate or restart the flow into a pipeline [8-11,13].

One challenge in the rheological characterization of waxy gels is the presence of apparent wall slip during rheometric measurements, which can lead to underestimated values for rheological properties, such as the yield stress [14-20]. As discussed by Barnes [14], apparent wall slip arises from the formation of a solvent-rich layer at the sample-wall interface,

\footnotetext{
a) Author to whom correspondence should be addressed; electronic mail: nele@eq.ufrj.br
}

which results from a combination of static and dynamic forces acting on the disperse phase adjacent to the walls. This solvent-rich layer at the walls, also termed as "depleted layer," can vary in a range from 0.02 to $10 \mu \mathrm{m}$ and facilitates any flow over solid boundaries because of the lubrication effect $[14,15,19]$.

The conditions that enhance apparent wall slip effects in flows of yield stress materials are encountered when large particles or drops as the disperse phase, low shear rates, smooth walls, and small dimensions are present[14]. These conditions are found in classical rheometric flows, such as parallel disks, cone and plate, and concentric cylinders, which highlight the importance of quantifying apparent wall slip effects on rheometric measurements $[14,15,19]$. To illustrate the phenomenon, schematic drawings describing apparent wall slip effects on the flow field inside parallel disks and concentric cylinders are shown in Figs. 1(a) and 1(b), respectively.

The detection of apparent wall slip in flows of suspensions and colloidal gels, including its physical description and correction methods, has already been subject of study by several researchers [14-20]. A recent review on this subject has been published by Cloitre and Bonnecaze [19]. Typical effects on rheometric measurements include false Newtonian plateaus at lower levels and kinks in the flow curve $[14,19]$. A common technique to prevent or, at least, mitigate these effects is to roughen the surface of the walls to disrupt the "depleted layer" [14,19]. It is generally observed that 

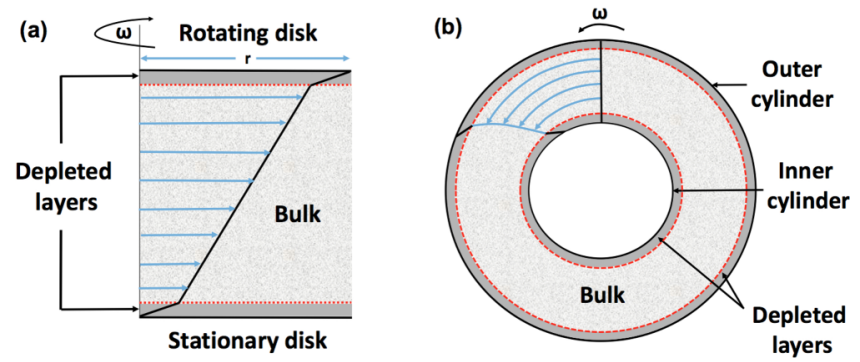

FIG. 1. Schematic representation of the apparent wall slip phenomenon in (a) parallel disks [adapted from Russel and Grant, Colloids Surf. 161, 2, 271-282 (2000). Copyright 2000, Elsevier Science B. V.] and (b) concentric cylinders, where the outer cylinder is rotated at angular velocity $\omega$ relative to the stationary inner cylinder [adapted from Yoshimura and Prud'homme, J. Rheol. 32, 53-67 (1988). Copyright 1988, The Society of Rheology, Inc.).

apparent wall slip is negligible when the roughness of the walls becomes much larger than the typical element size of dispersion $[14,19]$. It is worth mentioning that when the roughness becomes too large then flow between protrusions on the geometry surface can appear, which could lead to measurement errors [21,22]. Therefore, the suitable geometry choice is a fundamental part of the rheological analysis of materials prone to present apparent wall slip.

Typical profiled geometries employed to prevent apparent wall slip include (i) vane-in-cup, (ii) grooved concentric cylinders, and (iii) cross-hatched parallel disks. The vane-in-cup consists of a central shaft with thin blades arranged around at equal angles and an outer cylinder [23,24]. The vane is designed to work as an inner cylinder that shears the material in the bulk, thus preventing apparent wall slip on the inner surface [23,24]. The outer cylinder used with the vane frequently has a smooth surface, as it is generally assumed that apparent wall slip occurs mainly on the inner cylinder surface. This assumption is based on the work of Buscall et al.[15], who investigated apparent wall slip effects on rheometric measurements of concentrated dispersions. It is important to note, however, that Marchesini et al. [20] demonstrated that, in some circumstances, apparent wall slip is more pronounced at the outer cylinder surface, and that the grooved concentric cylinders perform better than the vane-incup in these cases. An alternative to the vane-in-cup and grooved concentric cylinders is the cross-hatched parallel disks $[21,22,25]$. This geometry consists of parallel disks with pyramidal pins regularly distributed on the entire surfaces in contact with the sample [21,25]. As discussed by Carotenuto et al. [21], when using this geometry, the flow between the pyramidal pins that resembles the flow through a porous medium at the walls can appear during rheometric measurements of some materials. In this case, this flow needs to be accounted for, so that accurate rheological properties can be obtained [21,22].

More recently, Bikos and Mason [26] fabricated customizable geometries via $3 \mathrm{D}$ printing for the rheological characterization of soft materials. Owens et al. [27] also employed 3D printing to produce the so-called fractal vanes as an attempt to optimize the rheological characterization of yield-stress materials. The authors investigated the performance of several fractal vanes by comparing the results with reference measurements obtained with a roughened cone and plate geometry [27]. It was found that a fractal vane with 24 arms, which in terms of rheological measurements is essentially the same as the grooved cylinder discussed in the literature [20], gives rise to the best results in terms of flow homogeneity and apparent wall slip prevention.

Concerning the rheological characterization of waxy gels, Wardhaugh and Boger [8-10] emphasized the importance of circumventing apparent wall slip effects on measurements of gelled waxy crude oils. Rønningsen [11] highlighted that apparent wall slip is not serious for gelled waxy crude oils having yield stress lower than $25 \mathrm{~Pa}$. Dimitriou et al. [28] employed a Rheo-PIV system to evaluate the presence of apparent wall slip in some rheological measurements of model gelled waxy oils. More recently, Marchesini et al. [12] pointed out that apparent wall slip is more pronounced for gels formed from model waxy oils. Even though significant progress has been made [8-10,12,28], there is still a need for quantifying, in a systematic way, apparent wall slip effects on the measurements of rheological properties of gelled waxy oils. This knowledge can be useful to assure meaningful rheological measurements and improve the design of transport processes of waxy gels.

In this paper, the effects of apparent wall slip on rheometric measurements of waxy gels are quantified for gels consisting of a macrocrystalline wax added to a mineral oil in concentrations of 3.0 and $7.5 \mathrm{wt}$ \%. Model waxy crude oils are adopted, because a complicating aspect of crude oils is the variability in the sample composition in terms of asphaltene, resins, and wax content [29]. A standard preparation protocol is followed to ensure reproducible rheological data $[10,12]$. Previous rheological measurements confirmed that these model systems reproduce essential features of crude oil gels, exhibiting a low-temperature gel-like mechanical response to an imposed low-frequency oscillatory stress [30]. The physicochemical and structural properties of the wax and solvent used can be found in our previous work ( $\mathrm{L}_{29}$ wax) [30]. Seven different geometry configurations are employed, including combinations of smooth and grooved surfaces at oscillatory, creep, and steady-state rheological experiments. The surface roughness of the geometries, wax crystals size, and the suitable aging time prior to yield stress measurements are discussed beforehand. The occurrence of apparent wall slip is investigated by comparing the results for the yield stress provided by oscillatory and creep tests performed with different geometry assemblies. The discussion is extended to encompass the storage modulus $\mathrm{G}^{\prime}$, and it is shown that $\mathrm{G}^{\prime}$ is strongly correlated to the yield stress for these systems [30]. Flow curves are also obtained and apparent wall slip is quantified as the relative difference between the areas under the curves obtained using geometries with smooth and grooved surfaces. In addition, apparent slip velocities are calculated for the smooth Couette geometry. Also, there is evidence that apparent wall slip affects the reproducibility of the data.

\section{MATERIALS AND METHODS}

\section{A. Model oil preparation}

Waxy crude oils are extremely sensitive to the thermal and shear histories experienced when cooled below the wax 
precipitation temperature [10]. Thus, model oils were freshly prepared under controlled conditions before each rheological test to avoid thermal and shear histories variation. Predominantly linear macrocrystalline wax with 29 carbons on average [30] and fusion range of $56-58^{\circ} \mathrm{C}$ was purchased from Sigma-Aldrich. Wax weight fractions of 3.0 and $7.5 \mathrm{wt}$. \% were employed for $30 \mathrm{~g}$ fluid in each preparation. The mixture was placed in a beaker and heated to $85^{\circ} \mathrm{C}$ for 15 min under magnetic stirring for complete wax solubilization. In this state, the samples behave as a Newtonian liquid and can be loaded into the rheometer and cooled in situ. The solvent employed is a spindle (mineral) oil provided by Petrobras; it is a nongelling mineral oil, free of crystallizable waxes at the temperature range assessed, presenting a boiling point of $315^{\circ} \mathrm{C}$, a density of $852 \mathrm{~kg} / \mathrm{m}^{3}$, and a viscosity of $2.39 \times 10^{-3}$ Pas at $20^{\circ} \mathrm{C}$.

\section{B. Rheological tests}

After preparation, samples were immediately placed on the rheometer. A DHR-3 controlled-stress rheometer (TA Instruments) was used, and the initial temperature was set to $50{ }^{\circ} \mathrm{C}$ for all tests. According to our previous measurements, this temperature is $22.7{ }^{\circ} \mathrm{C}$ higher than the wax precipitation temperature of the $7.5 \mathrm{wt}$ \% system [30].

Three types of postcooling tests were performed, namely (i) oscillatory tests, (ii) creep, and (iii) steady-state flow tests. The rheological protocol comprises four steps. The first three steps were identical for all tests:

- Step [1] - two minutes of thermal equilibration at $50{ }^{\circ} \mathrm{C}$;

- Step [2]—quiescent cooling from 50 to $4{ }^{\circ} \mathrm{C}$ at $1.0^{\circ} \mathrm{C} / \mathrm{min}$ rate; and

- Step [3] - 30 min of isothermal holding at $4{ }^{\circ} \mathrm{C}$ to obtain a gelled material.

In the case of postcooling oscillatory tests, the last step was as follows:

- Step [4a] - a logarithmic stress amplitude sweep at $4{ }^{\circ} \mathrm{C}$ and $1.0 \mathrm{~Hz}$ from 1 to $500 \mathrm{~Pa}$ (3.0 wt. \% systems) or 1 to $2700 \mathrm{~Pa}$ ( $7.5 \mathrm{wt} . \%$ systems). For these oscillatory tests, the yield stress was defined as the $G^{\prime}$ and $G^{\prime \prime}$ crossing point. This definition provides a fast method to probe a wide experimental range [31].

In the case of postcooling creep tests, the last step was as follows:

- Step [4b]—an imposed constant stress value to the sample for 2 min at $4{ }^{\circ} \mathrm{C}$. For these creep tests, the yield stress was defined as the first value of stress that causes a marked increase in the geometry angular speed.

In the case of postcooling steady-state flow tests, the last step was as follows:

- Step [4c] - flow curves with the shear rate varying logarithmically from $10^{-3}$ to $10^{3} \mathrm{~s}^{-1}$, equilibration time of 150 and $30 \mathrm{~s}$ sampling. For these steady-state flow tests, the yield stress is estimated by extrapolation of data to the zero shear rate.
In oscillatory tests, all experiments were run in triplicate. The 95\% confidence interval was calculated using Student's t-test. According to an international interlaboratory study for yield stress measurements, direct methods were found to produce more reproducible results than indirect methods [32].

\section{Geometries}

Figure 2 shows all the geometry elements employed. Smooth cylinder, grooved cylinder, four-bladed vane, smooth upper plate, and grooved upper plate are the moving parts, whereas the smooth cup, the grooved cup, and the smooth Peltier plate are the stationary parts.

Seven different assemblies were used in the rheological tests:

- SPP—smooth parallel plate (with smooth Peltier plate);

- GPP—grooved parallel plate (with smooth Peltier plate);

- SC + SC - smooth cylinder + smooth cup;

- SC + GC-smooth cylinder + grooved cup;

- $\mathrm{GC}+\mathrm{SC}$ - grooved cylinder + smooth cup;

- $\mathrm{GC}+\mathrm{GC}$ - grooved cylinder + grooved cup; and

- V + GC-vane + grooved cup.

The dimensions for each geometry are described as follow:

- Smooth cylinder and grooved cylinder: bob diameter $28.05 \mathrm{~mm}$, bob length $50.00 \mathrm{~mm}$;

- Smooth cup and grooved cup: $30.50 \mathrm{~mm}$ diameter;

- The grooved cylinder has 18 grooves and an internal diameter of $25.75 \mathrm{~mm}$. Each groove has $2.3 \mathrm{~mm}$ height and $0.40 \mathrm{~mm}$ width, and they are equally spaced by $4.75 \mathrm{~mm}$;

- Vane: four-bladed elements equally distributed at the central shaft that connects to the rheometer, $1.20 \mathrm{~mm}$ thickness and $41.9 \mathrm{~mm}$ height; and

- Smooth and grooved parallel plates: $60 \mathrm{~mm}$ diameter. In this case, both geometries were assembled with a smooth Peltier plate and a fixed gap of $800 \mu \mathrm{m}$.

Table I lists all rheological tests performed, according to the experiment type, system composition, and geometry assembly.

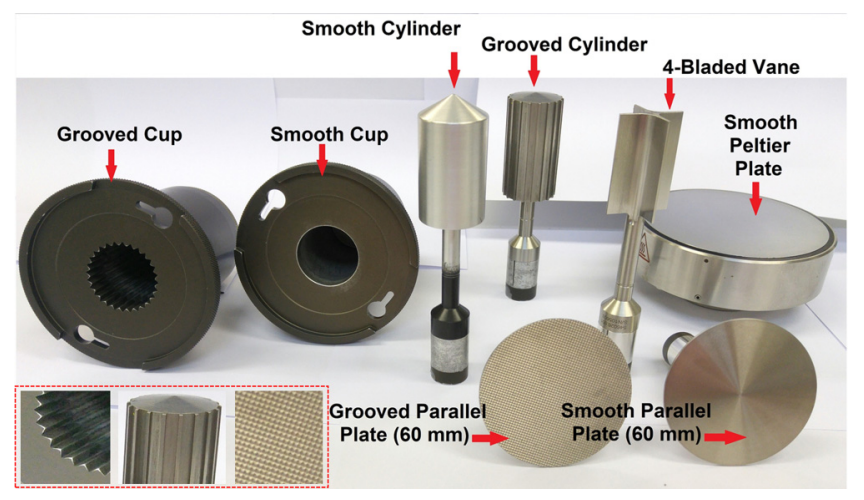

FIG. 2. Geometry elements employed in the experiments. Different assemblies were tested by combining these elements. Grooved cup, grooved cylinder, and grooved parallel plate are shown in detail. 
TABLE I. Rheological tests performed according to the composition and geometry employed.

\begin{tabular}{lcc}
\hline \hline & $3.0 \mathrm{wt} . \%$ & $7.5 \mathrm{wt} . \%$ \\
\hline Oscillatory tests & $\mathrm{SPP}$ & $\mathrm{SC}+\mathrm{SC}$ \\
& $\mathrm{GPP}$ & $\mathrm{SC}+\mathrm{GC}$ \\
& $\mathrm{SC}+\mathrm{SC}$ & $\mathrm{GC}+\mathrm{SC}$ \\
& $\mathrm{SC}+\mathrm{GC}$ & $\mathrm{GC}+\mathrm{GC}$ \\
& $\mathrm{GC}+\mathrm{SC}$ & \\
& $\mathrm{GC}+\mathrm{GC}$ & - \\
Creep tests & $\mathrm{V}+\mathrm{GC}$ & - \\
& $\mathrm{SC}+\mathrm{SC}$ & $\mathrm{SC}+\mathrm{SC}$ \\
Steady-state flow tests & $\mathrm{GC}+\mathrm{GC}$ & $\mathrm{GC}+\mathrm{GC}$ \\
& $\mathrm{SC}+\mathrm{SC}$ & \\
\hline \hline
\end{tabular}

\section{Surface roughness measurements}

The roughness profiles of the cylindrical geometries were assessed using a contact profilometer Form Talysurf 50 (Taylor Hobson). For the parallel plate geometries, a Dektak XT (Bruker) profilometer was employed. The traversing length was set to $2000 \mu \mathrm{m}$, and five runs were performed for each geometry. The $95 \%$ confidence interval was provided by Student's t-test. The surface roughness was expressed by the average roughness, $R_{a}$. This is the most used and universally recognized parameter of roughness [33]. It is defined as the arithmetic average of absolute values of the measured profiles height deviations taken with the sampling length relative to the center line (a line parallel to the general direction of the roughness profile). $R_{a}$ is given by the following equation [33]:

$$
R_{a}=\frac{1}{L} \int_{x=0}^{x=L}|y| \mathrm{d} x
$$

where $L$ represents the sampling length and $y$ is the ordinate of the curve profile.

\section{Optical microscopy}

Polarized light optical microscopy was adopted to measure the size of precipitated wax crystals. Visualizations were made with an inverted Axio Imager 2 microscope (Carl Zeiss) equipped with MRc5 Axiocam (5.0 megapixels) and a temperature controller (Linkan T95-PE) with 20x objective lens (200× magnification).

A small sample volume $(\sim 0.05 \mathrm{ml})$ of freshly prepared model oil $7.5 \mathrm{wt}$. \% was placed on viewing slides positioned on the thermal stage of the microscope preheated at $50^{\circ} \mathrm{C}$ for $5 \mathrm{~min}$. Next, the sample was cooled at $1.0^{\circ} \mathrm{C} / \mathrm{min}$ until $4{ }^{\circ} \mathrm{C}$. All images were acquired with Axio Vision 4.8 software. The crystals length and aspect ratio (defined as the ratio of the minor to the major axis) were averaged for 125 random measurements.

\section{RESULTS AND DISCUSSION}

This section gathers results from surface roughness, optical microscopy, and rheological tests. First, the roughness values obtained for the smooth and grooved geometries as well as the size of precipitated wax crystals are discussed. Then, the importance of a time sweep step prior to yield stress measurements is discussed. After that, there is an analysis of apparent wall slip effects on the storage modulus and yield stress provided by oscillatory tests. The strategy is to start from similar stable waxy gels and assess these rheological properties with geometries of different surface roughnesses. Thus, the effects of apparent wall slip can be analyzed and quantified by comparing the results from geometries progressively more roughened. The yield stress obtained by oscillatory tests is compared with results from creep tests, confirming the trend previously observed. For creep tests, two representative geometries were selected, the smooth Couette and the grooved concentric cylinders. The steady-state flow behavior of waxy gels is assessed with the two representative geometries, demonstrating how the flow curves can be affected by apparent wall slip. A quantitative analysis of the apparent slip velocity is also provided, and the potential impact of the results obtained on pipeline transportation is discussed.

\section{A. Surface roughness and wax crystals size}

The surface roughness of the geometries employed to obtain the rheological data is summarized in Table II. In this table, the absolute roughness of pipes commonly used in the oil industry is also provided.

Considering the smooth geometries, the average roughness is quite similar $\left(R_{a}=0.18 \mu \mathrm{m}\right.$, on average), except for the smooth cup, which has a roughness $\sim 3.5$ times higher, but still below $1 \mu \mathrm{m}$. As a comparison, Dimitriou et al. [28] performed rheological measurements with a $4^{\circ}$ angle cone with radius $R=25 \mathrm{~mm}$ and surface roughness $R_{\mathrm{q}}=0.6 \mu \mathrm{m}$ $\left(\mathrm{R}_{\mathrm{a}} \sim 5.45 \mu \mathrm{m}\right)$. When applying specific adhesive-backed sandpaper, the roughness was increased to $R_{\mathrm{q}}=30 \mu \mathrm{m}$

TABLE II. Surface roughness of rheometric geometries and commonly used pipes for oil transport.

\begin{tabular}{cc}
\hline \hline Geometry part (see Fig. 2) & $\begin{array}{c}\text { Average roughness- } \mathrm{R}_{\mathrm{a}} \\
(\mu \mathrm{m})\end{array}$ \\
\hline Smooth Peltier plate & $0.17 \pm 0.01$ \\
Smooth parallel plate & $0.15 \pm 0.01$ \\
Grooved parallel plate & $87 \pm 2$ \\
Smooth cylinder $^{\text {Grooved cylinder }}{ }^{\mathrm{a}}$ & $0.21 \pm 0.01$ \\
Smooth cup & $0.31 \pm 0.02$ \\
Grooved cup $^{\mathrm{a}}$ & $0.61 \pm 0.01$ \\
4-bladed vane & $0.37 \pm 0.01$ \\
Type of pipe & $0.26 \pm 0.01$ \\
Bare steel pipe [35] & Absolute surface roughness $(\mu \mathrm{m})$ \\
Typical subsea operations pipes [34] & $30-50 \mu \mathrm{m}$ \\
Internally coated pipes [35] & $12 \mu \mathrm{m}$ \\
\hline \hline
\end{tabular}

${ }^{\mathrm{a}}$ These values are referred to longitudinal measurements. 
$\left(\mathrm{R}_{\mathrm{a}} \sim 27.3 \mu \mathrm{m}\right) . \mathrm{R}_{\mathrm{q}}$ is defined as the root mean square deviation of the surface profile.

The four-bladed vane presents a small $R_{a}$ value of $0.26 \mu \mathrm{m}$. However, the proven ability of the vane geometry to mitigate apparent wall slip $[23,24]$ is not related to the average roughness $R_{a}$ of the surface, but to the fact that the vane geometry is a profiled geometry that allows the sample to be sheared in the bulk. Therefore, the small microscopic roughness measured at the blades can only explain possible apparent wall slip at the blades' tip, which is expected to be negligible, as only a small portion of the sample is sheared at the blades' tip. The same rationale applies to the grooved cylinder and grooved cup, which present $R_{a}$ values of 0.31 and $0.37 \mu \mathrm{m}$, respectively. As these small $\mathrm{R}_{\mathrm{a}}$ values were obtained longitudinally, this microscopic roughness can also only explain possible apparent wall slip at the protrusions tip of the grooved cylinder and grooved cup. At a macroscopic level, the solid boundaries of the grooved cylinder and grooved cup possess noticeable protrusions that also allow these geometries to shear the sample in the bulk. In the case of grooved cylinder, for example, the grooves have $2.3 \mathrm{~mm}$ height, $0.40 \mathrm{~mm}$ width, and are equally spaced by $4.75 \mathrm{~mm}$.

The so-called grooved parallel plate presents a large $R_{a}$ value of $87 \mu \mathrm{m}$, which results from the more widely spaced components of surface texture that lead to an increased waviness for this geometry [33]. This can be seen in Fig. 3, where a comparison between representative roughness profiles of the smooth parallel plate (SPP) and grooved parallel plate (GPP) is provided.

The average length of precipitated wax crystals for the 7.5 wt. $\%$ model oil at $25^{\circ} \mathrm{C}$ is provided $(25 \pm 3 \mu \mathrm{m})$. In Fig. 4, the morphology and structural evolution of waxy crystals precipitated during the cooling process assessed by the polarized light technique are shown. The freshly prepared sample was quiescently cooled inside the microscopy thermal stage from 50 to $4{ }^{\circ} \mathrm{C}$ at $1.0^{\circ} \mathrm{C} / \mathrm{min}$. At $25^{\circ} \mathrm{C}$, it is possible to observe a significant amount of needle-like crystals (aspect ratio of $0.11 \pm 0.02$ ) amassed into clusters of

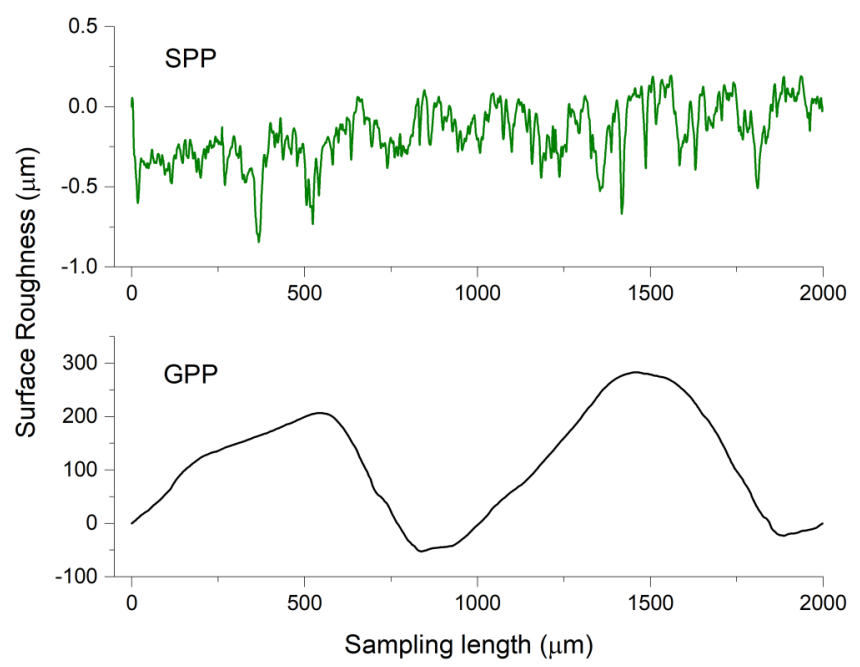

FIG. 3. Representative roughness profile: smooth parallel plate geometry (top) and grooved parallel plate (bottom).

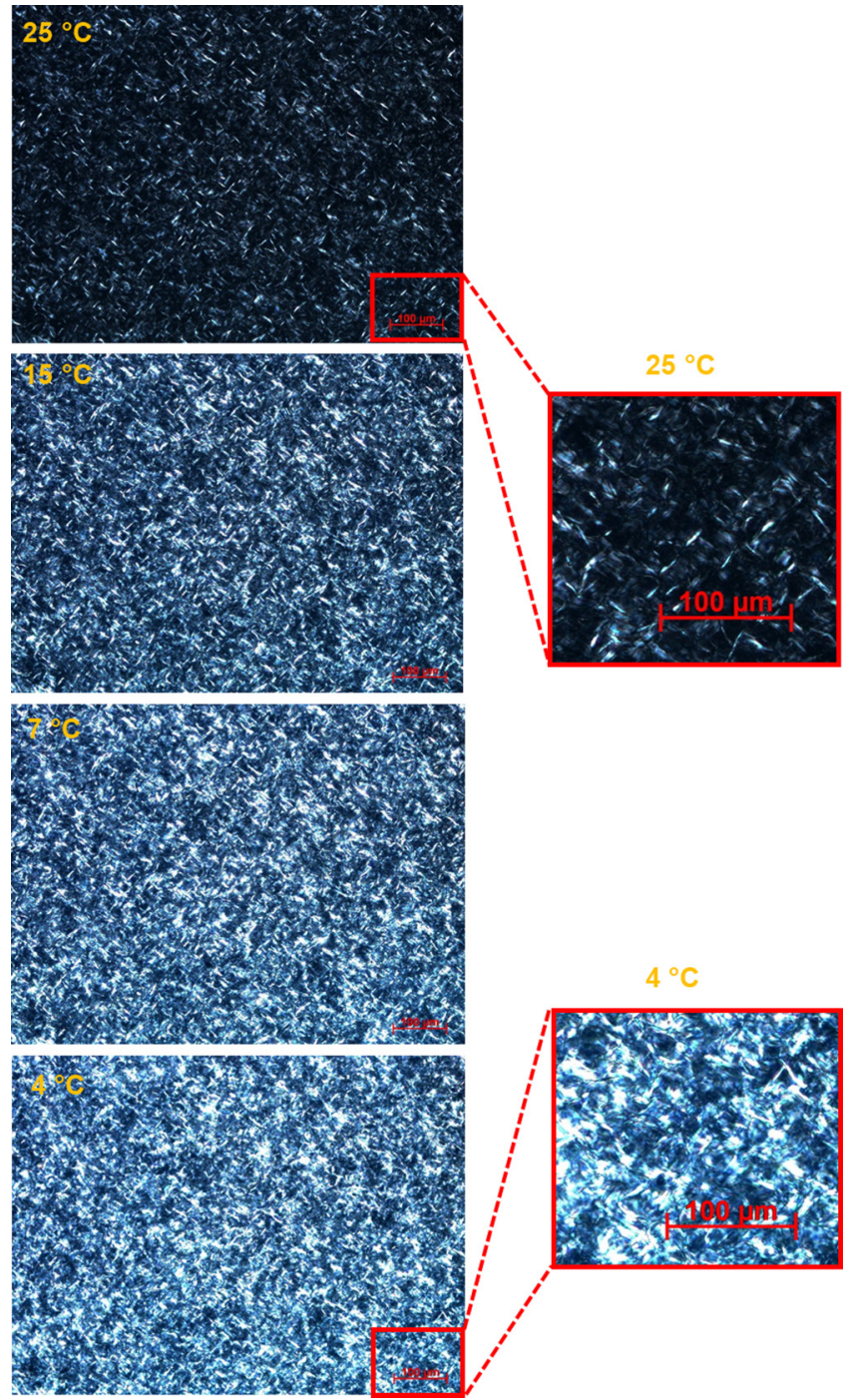

FIG. 4. Precipitated wax crystals from freshly prepared $\mathrm{L}_{29} 7.5 \mathrm{wt} \%$ model oil cooled quiescently from 50 to $4{ }^{\circ} \mathrm{C}$ at $1.0^{\circ} \mathrm{C} / \mathrm{min}$ (200× magnification).

varying sizes. The size and the number of crystals increased because of the continuous precipitation of waxes during cooling. Also, the floc compactness is visibly affected when the image details at 25 and $4{ }^{\circ} \mathrm{C}$ are compared.

It is worth mentioning that three possible morphologies are reported for wax crystals, namely, amorphous malformed crystals, needles, or platelets, and that the final crystals' shape depends on oil composition, cooling rate during crystallization, and thermal and shear histories [36-38]. Singh et al. [39] discussed the changes in the morphology of wax crystals with the cooling rates based on results by Dirand et al. [40] They inferred that needle-shaped crystals were formed during slow cooling under static conditions, while under flow conditions platelet-like crystals were formed with an amorphous solid material. Létoffé et al. [41] investigated model oils and 14 crude oil samples. Their results indicated that the crystals size depend directly on the length of the waxy chains. Also, the crystals size observed at $-20^{\circ} \mathrm{C}$ was always small, between 1 and $3 \mu \mathrm{m}$, even when different cooling rates were employed ( 2 or $0.5^{\circ} \mathrm{C} / \mathrm{min}$ ). Cazaux et al. [42] performed optical microscopy experiments with crude oils on a thermostated 
stage. The authors observed anisotropic particles having the shape of needles. The slower the cooling rate, the longer the needles. Crystal lengths were also measured between 1 and $10 \mu \mathrm{m}$ and their diameters in the order of $1 \mu \mathrm{m}$.

By comparing the surface roughness of the grooved parallel plates $(87 \mu \mathrm{m})$ with the average length of precipitated wax crystals $(25 \pm 3 \mu \mathrm{m})$ assessed in this work, it is possible to note that the surface roughness of the rheometer geometry is approximately 3.4 times larger than typical wax crystals. Therefore, several wax crystals can be trapped in the space between the rugosity of this geometry, thus disturbing the "depleted layer," which can mitigate apparent wall slip effects. For smooth geometries, the surface roughness is only about $0.8 \%$ of the average crystals size obtained. Thus, in this case, the wax crystals cannot be retained in the microscopic cavities of the solid boundary, which is only accessible for the fluid phase. Therefore, more significant apparent wall slip effects are expected for smooth geometries.

\section{B. Cooling process under oscillatory shear: Aging time for structure buildup}

After placing the samples in the rheometer at the initial temperature of $50{ }^{\circ} \mathrm{C}$, a controlled cooling process was imposed to the samples until $4{ }^{\circ} \mathrm{C}$ was achieved. At this temperature, an isothermal holding time of $30 \mathrm{~min}$, known as aging time, was employed prior to all postcooling rheological tests conducted in this work to provide a sufficient time by which all samples achieve a similar level of structure. This is an important step to allow for more reproducible results in terms of yield stress [43] (see Sec. II B). During this aging time, there is an increase in the storage modulus because of the presence and expansion of a crystalline network, composed mainly of wax crystals [44]. Therefore, the evolution of the storage modulus as a function of time can indicate whether or not the system has reached structural equilibrium.

The particular choice for $30 \mathrm{~min}$ as aging time relies on the fact that, for the two compositions investigated, the average value of storage modulus increases slowly during this period, considering that the aging time is a step applied after cooling the samples to $4{ }^{\circ} \mathrm{C}$. To illustrate this fact, $\mathrm{G}^{\prime}$ was measured for the $3.0 \mathrm{wt} \%$ system during two subsequent steps: oscillatory cooling from 50 to $4{ }^{\circ} \mathrm{C} \quad\left(\mathrm{d} T / \mathrm{d} t=1.0^{\circ} \mathrm{C} / \mathrm{min}\right.$, oscillatory stress $=0.1 \mathrm{~Pa}$, and frequency $=1.0 \mathrm{~Hz}$ ) followed by a time sweep step of $100 \mathrm{~min}$, as shown in Fig. 5. Before temperature reaches $23{ }^{\circ} \mathrm{C}$, the major part of the wax crystals were solubilized in the oil matrix, reflecting in very low and approximately constant value of $\mathrm{G}^{\prime}\left(\sim 10^{-4} \mathrm{~Pa}\right)$, which indicates that no structured material is present in the sample. Then, a step increase in $\mathrm{G}^{\prime}$ can be observed at $23{ }^{\circ} \mathrm{C}$, indicating that from this temperature onward the precipitated wax crystals are able to build a spanning waxy network that leads to oil gelation. As cooling proceeds, the abrupt change in storage modulus vanishes at $10^{\circ} \mathrm{C}$, i.e., before the system reaches the final cooling temperature. The "aging" begins when the temperature reaches $4{ }^{\circ} \mathrm{C}$. At this temperature, $\mathrm{G}^{\prime}$ has already increased around nine orders of magnitude when compared to the initial temperature of $50{ }^{\circ} \mathrm{C}$. It is important to note that there are no significant

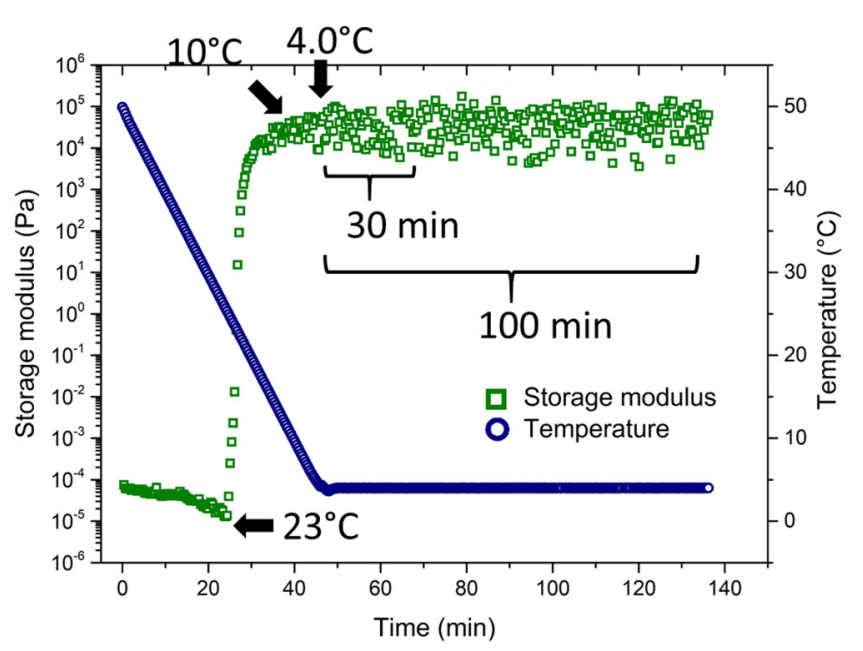

FIG. 5. Storage modulus for $3.0 \mathrm{wt} \%$ system measured at two subsequent steps: oscillatory cooling from 50 to $4{ }^{\circ} \mathrm{C}$ followed by a time sweep of $100 \mathrm{~min}$. The buildup of the waxy network structure mainly occurs between 23 and $10{ }^{\circ} \mathrm{C}$. At the final cooling temperature of $4{ }^{\circ} \mathrm{C}$, the structure is fairly stable after $30 \mathrm{~min}$, as indicated by the storage modulus measurements.

changes in $\mathrm{G}^{\prime}$ during the aging period, indicating that the structure buildup process occurs mainly during cooling.

\section{Postcooling rheometric measurements}

\section{Oscillatory tests: Apparent wall slip effects on yield stress and $\mathbf{G}^{\prime}$}

The yield stress, storage modulus $\mathrm{G}^{\prime}$, and loss modulus $\mathrm{G}^{\prime \prime}$ are obtained from oscillatory rheometric experiments performed at $4{ }^{\circ} \mathrm{C}$ for the 3.0 and $7.5 \mathrm{wt}$. \% systems. The results of the $3.0 \mathrm{wt}$. \% system for different geometries are presented in Fig. 6.

It can be seen in Fig. 6 that $G^{\prime}$ is significantly higher than $\mathrm{G}^{\prime \prime}$ in the range of small stress amplitudes for all geometries employed, indicating that the waxy gel presents a predominant elastic response in this range. In addition, it is possible to identify a region of linear viscoelastic behavior [45], in which both $\mathrm{G}^{\prime}$ and $\mathrm{G}^{\prime \prime}$ are approximately constant and denoted as $\mathrm{G}_{\mathrm{LVR}}^{\prime}$ and $\mathrm{G}^{\prime \prime}{ }_{\mathrm{LVR}}$ in this text. As discussed by Chang et al. [46], this behavior suggests that the interlocking network of waxy crystals is not degraded in this region. For sufficiently high stress amplitudes, $G^{\prime}$ starts to decrease in a higher rate than $G^{\prime \prime}$, indicating a creep response for the waxy gel. When the stress amplitude is further increased, then an abrupt decrease in both $\mathrm{G}^{\prime}$ and $\mathrm{G}^{\prime \prime}$ is observed, and a crossing point can be identified, above which $\mathrm{G}^{\prime \prime}$ becomes higher than $\mathrm{G}^{\prime}$. This crossing point is considered as a measure of the yield stress, because this point indicates a change from solidlike to liquid-like behavior [46]. As discussed by Wardhaugh and Boger [10], this dramatic change in behavior observed for waxy gels suggests that the yielding of waxy gels resembles the fracture of solids.

With regard to the impact of different geometries on these results, it is possible to observe in Fig. 6 a change in slope in the \%strain curves for all geometries, except for the allgrooved ones, i.e., $\mathrm{GC}+\mathrm{GC}$ and $\mathrm{V}+\mathrm{GC}$. In addition, it can be seen that the crossing point between $G^{\prime}$ and $G^{\prime \prime}$ occurs at 

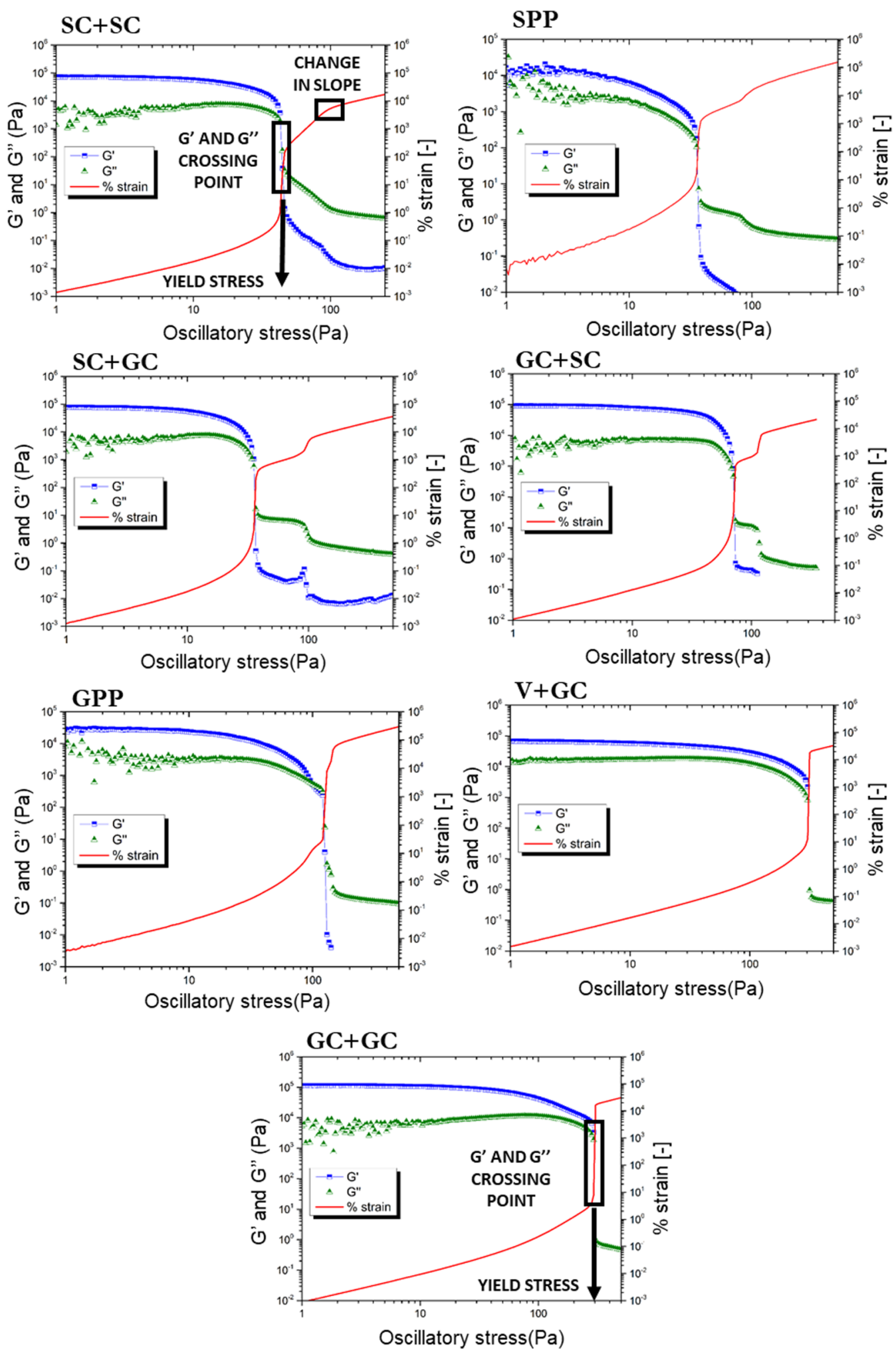

FIG. 6. Stress amplitude sweeps for the $3.0 \mathrm{wt}$ \% model oil performed with seven different geometries. It is possible to observe that after the $\mathrm{G}^{\prime}$ and $\mathrm{G}^{\prime \prime}$ crossing point, the storage modulus is still being captured for all geometries, except for the all-grooved GC $+\mathrm{GC}$ and $\mathrm{V}+\mathrm{GC}$. Also, there is a kink in the \%strain curve for all geometries, except for GC+GC and V+GC.

a lower level of stress amplitude for geometries including smooth parts. These findings can be explained as apparent wall slip effects.

Similar behavior for the storage modulus was reported by Walls et al. [18], who investigated the apparent wall slip of colloidal gels and verified a second plateau for $G^{\prime}$ at oscillatory rheological tests with smooth surfaces, which was absent with a grooved geometry. The authors assumed that at moderately high stress amplitudes, which correspond to the second $\mathrm{G}^{\prime}$ plateau, apparent wall slip may occur due to a thin layer of particle-lean fluid near the walls deforming more than the bulk of the material. At sufficiently large stress 
amplitudes, the gel structure is entirely disrupted, and the bulk material begins to flow and approaches the behavior observed with grooved geometry assessed (serrated parallel plates). An alternative explanation brought up by the authors for the presence of two $\mathrm{G}^{\prime}$ plateaus was the existence of two types of microstructures in the colloidal gels. The disruption of each structure would correspond to the catastrophic drop in $\mathrm{G}^{\prime}$ (this is seen in Fig. 6 for SC + SC and SC + GC geometry). However, if such scenario existed, the dual plateau and drop-off behavior would have remained with the use of grooved geometries.

Another perspective is provided by Barnes [14]. According to this author, for materials as attractive colloids, when a smooth surface is present, apparent wall slip occurs for stress levels lower than the yield stress. When the yield stress is exceeded, apparent wall slip tends to become negligible.

The yield stress values evaluated for both 3.0 and 7.5 wt. \% systems with all geometry configurations employed are summarized in Table III and plotted in Fig. 7. In this figure, it becomes clear that the all-grooved geometries provide much higher yield stress values for both concentrations, indicating that apparent wall slip occurs in both the stationary and moving geometry parts for these systems. It is worth noting that the yield stress value strongly depends on the total amount of wax in the oil, as expected [6,47]. In particular, the yield stress of the $7.5 \mathrm{wt}$ \% model oil is about 10 times higher when compared to the $3.0 \mathrm{wt}$. \% system; thus, a 10 -fold increase is observed when the amount of wax is increased two and a half times in this concentration range.

Besides the yield stress values, Table III also summarizes the relative percentage error in yield stress $\left(\sigma_{\mathrm{y}} \mathrm{RPE}\right)$ and the storage modulus at the linear viscoelastic region $\left(G_{L V R}^{\prime}\right)$, measured with different geometry configurations. $\sigma_{\mathrm{y}}$ RPE is defined as the yield stress uncertainty provided by Student's t-test divided by its average value, while $\mathrm{G}_{\mathrm{LVR}}^{\prime}$ is calculated as an average between the $\mathrm{G}^{\prime}$ values at the linear viscoelastic region.

In Table III, it can be seen that for the $3.0 \mathrm{wt}$. \% system, the yield stress value obtained with geometries having

TABLE III. Yield stress, $\sigma_{y}$ RPE, and $G_{L V R}^{\prime}$ for different geometries and two compositions. "*” denotes (yield stress uncertainty divided by its average value) $* 100 \%$.

\begin{tabular}{lccc}
\hline \hline & \multicolumn{2}{c}{3.0 wt. $\%$ model oil } \\
\hline Geometry & $\sigma_{\mathrm{y}}(\mathrm{Pa})$ & $\sigma_{\mathrm{y}} \mathrm{RPE}(\%)^{*}$ & $\mathrm{G}_{\mathrm{LVR}}^{\prime}(\mathrm{kPa})$ \\
\hline $\mathrm{SPP}$ & $40 \pm 15$ & 37.5 & $13 \pm 1.4$ \\
$\mathrm{SC}+\mathrm{SC}$ & $40 \pm 8$ & 20 & $74 \pm 7.1$ \\
$\mathrm{SC}+\mathrm{GC}$ & $42 \pm 10$ & 23.8 & $67 \pm 2.0$ \\
$\mathrm{GC}+\mathrm{SC}$ & $64 \pm 25$ & 39 & $86 \pm 9.8$ \\
$\mathrm{GPP}$ & $106 \pm 34$ & 32.1 & $25 \pm 1.9$ \\
$\mathrm{GC}+\mathrm{GC}$ & $259 \pm 26$ & 10 & $109 \pm 1.3$ \\
$\mathrm{~V}+\mathrm{GC}$ & $259 \pm 24$ & 10.8 & $61 \pm 1.3$ \\
& $7.5 \mathrm{wt} \%$ model oil & \\
\hline $\mathrm{SC}+\mathrm{SC}$ & $488 \pm 102$ & 20.1 & $259 \pm 23$ \\
$\mathrm{SC}+\mathrm{GC}$ & $696 \pm 130$ & 18.7 & $523 \pm 66$ \\
$\mathrm{GC}+\mathrm{SC}$ & $1454 \pm 210$ & 14.4 & $682 \pm 37$ \\
$\mathrm{GC}+\mathrm{GC}$ & $2700 \pm 252$ & 9.33 & \\
\hline \hline
\end{tabular}

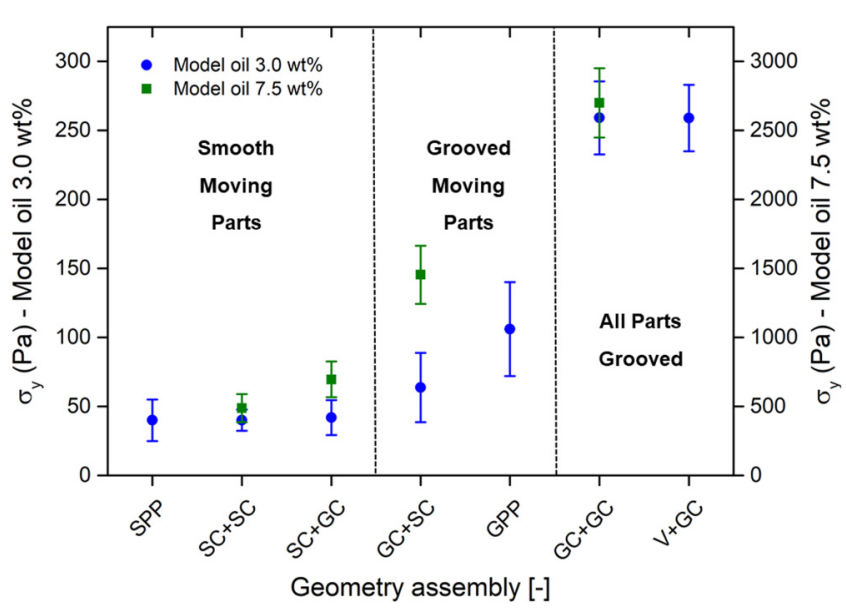

FIG. 7. Yield stress results for $3.0 \mathrm{wt}$ \% (filled circles) and $7.5 \mathrm{wt} . \%$ (filled squares) model oils measured with different geometry configurations. The 95\% confidence interval was calculated using Student's t-test.

smooth moving parts ( $\mathrm{SPP}, \mathrm{SC}+\mathrm{SC}$, and $\mathrm{SC}+\mathrm{GC}$ ) is roughly $41 \mathrm{~Pa}$, a value $84 \%$ lower than the $259 \mathrm{~Pa}$ obtained with the all-grooved geometries $(\mathrm{GC}+\mathrm{GC}$ and $\mathrm{V}+\mathrm{GC})$. This result quantifies the apparent wall slip effects in the yield stress measurements performed with SPP, SC + SC, and $\mathrm{SC}+\mathrm{GC}$ geometries. For the all-grooved geometries, besides the higher yield stress obtained, there is a clear increase in reproducibility, as the average of $\sigma_{\mathrm{y}} \mathrm{RPE}$ for $\mathrm{GC}+\mathrm{GC}$ and $\mathrm{V}+\mathrm{GC}$ is $10.4 \%$, which is significantly lower than the $27.1 \%$ for the geometries with smooth moving parts SPP, $\mathrm{SC}+\mathrm{SC}$, and $\mathrm{SC}+\mathrm{GC}$.

One aspect that is worth noting in Table III emerges from the comparison of the yield stress values obtained with the smooth parallel plate, SPP, and the grooved parallel plate, GPP. In this case, from SPP to GPP, there is an increase only in the roughness of the moving geometry part, whereas the stationary part remains the same smooth Peltier plate. By comparing these measurements, an increase of $165 \%$ in the yield stress value with the GPP is observed. Identical rationale can be applied to analyze the results obtained with the smooth cylinder + smooth cup and grooved cylinder + smooth cup, as the same trend is observed. This indicates that introducing grooved moving surfaces mitigates apparent wall slip effects, as expected. If we compare the yield stress measured with GPP (106 Pa) to the yield stress from allgrooved geometries $(259 \mathrm{~Pa})$, an increase of $144 \%$ is obtained. When the same comparison is made for $\mathrm{GC}+\mathrm{SC}$ (64 Pa), the increase is $300 \%$. Therefore, it is clear that the trade between a smooth to a grooved moving part mitigates but does not eliminate apparent wall slip effects in the measurements. Only by using all-grooved geometries that apparent wall slip can be prevented in the systems evaluated. Also, taking into account the results for yield stress obtained with $\mathrm{SC}+\mathrm{GC}$ (42 Pa), GC + SC (64 Pa), and GPP (106 Pa), we can infer that the apparent wall slip is more pronounced when the moving part of the geometry is smooth.

With regard to the $7.5 \mathrm{wt}$. \% model oil, four representative geometries were employed, namely, smooth cylinder + smooth cup, smooth cylinder + grooved cup, grooved cup + smooth cylinder, and grooved cylinder + grooved cup. Analyzing 
Table III, the same rationale can be applied here regarding the yield stress results. For example, when comparing the values for SC + SC geometry (488 Pa) to GC + GC (2700 Pa), there is a decrease of $82 \%$ in yield stress when the smooth geometry is used. It is approximately the same decrease calculated for the $3.0 \mathrm{wt} . \%$ system, suggesting that apparent wall slip is not composition-dependent for oscillatory tests, at least in the range assessed in this work. The reproducibility of the results is also enhanced for $\mathrm{GC}+\mathrm{GC}$ geometry $\left(\sigma_{\mathrm{y}} \mathrm{RPE} 9.33 \%\right)$ when compared to $\mathrm{SC}+\mathrm{SC}\left(\sigma_{\mathrm{y}} \mathrm{RPE} 20.1 \%\right)$. As a comparison, Walls et al. [18] reported a reduction in yield stress of approximately $62 \%$ when smooth surfaces are compared to serrated surfaces for colloidal silica gels with different compositions. Additionally, intermediate values between the lowest and highest yield stress are observed. From SC + GC (696 Pa) to $\mathrm{GC}+\mathrm{SC}(1454 \mathrm{~Pa})$, there is an increase in the yield stress value, once again indicating that apparent wall slip is more pronounced when the moving part of the geometry is smooth.

The analysis of apparent wall slip effects on the storage modulus $\mathrm{G}^{\prime}$ is based on the $\mathrm{G}_{\mathrm{LVR}}^{\prime}$ values shown in Table III. When concentric cylinder geometries are compared $(\mathrm{SC}+\mathrm{SC}, \mathrm{SC}+\mathrm{GC}, \mathrm{GC}+\mathrm{SC}$, and $\mathrm{GC}+\mathrm{GC}), \mathrm{G}_{\mathrm{LVR}}^{\prime}$ is a clear function of the geometry roughness, regardless of the system composition. The same trends observed for the yield stress results apply for $\mathrm{G}_{\mathrm{LVR}}^{\prime}$, i.e., (i) when a geometry with a smooth moving part is employed, $\mathrm{G}_{\mathrm{LVR}}^{\prime}$ presents the lowest value; (ii) an intermediate value is achieved when a grooved moving part is used with a smooth stationary part; and (iii) the highest $\mathrm{G}_{\mathrm{LVR}}^{\prime}$ is obtained for the all-grooved geometry. There are several investigations pointing to the correlation between yield stress and storage modulus for drilling fluids [48], waxy crude oil $[49,50]$, and model waxy oil $[30,51]$. In the particular case of waxy gels, both properties arise from the same phenomenon, i.e., oil gelation [52]; thus, it is reasonable to assume a strong correlation of both properties, as described in our previous study [30,51].

When the all-smooth $\mathrm{SC}+\mathrm{SC}$ geometry is compared to the all-grooved $\mathrm{GC}+\mathrm{GC}$ geometry, the decrease in $\mathrm{G}_{\mathrm{LVR}}^{\prime}$ is of $32 \%$ for $3.0 \mathrm{wt}$. $\%$ model oil and $62 \%$ for $7.5 \mathrm{wt} . \%$ model oil. Thus, in these cases, the macroscopic protuberances have a clear influence in the storage modulus, which is underestimated when measured with geometries having smooth parts. For the $3.0 \mathrm{wt}$ \% model oils, it is possible to note that the SPP geometry provides a $\mathrm{G}_{\text {LVR }}^{\prime}$ of $13 \mathrm{kPa}$, which is significantly lower than the $\mathrm{G}_{\mathrm{LVR}}^{\prime}$ of $74 \mathrm{kPa}$ obtained with the $\mathrm{SC}+\mathrm{SC}$ geometry. This difference can be related to distinct apparent wall slip effects for the two geometry configurations, which can arise from a difference in the surface roughness (note in Table II that $R_{a}$ is $\sim 3$ times higher for the smooth cup) and in the surface area.

At last, in Fig. 8, it is possible to see representative $\mathrm{G}^{\prime}$ curves for all-grooved $(\mathrm{GC}+\mathrm{GC})$ and all-smooth $(\mathrm{SC}+\mathrm{SC})$ geometries obtained from stress amplitude sweeps for the $3.0 \mathrm{wt}$ \% system. The reproducibility of the results is clearly improved, as the standard deviation of $\mathrm{G}_{\mathrm{LVR}}^{\prime}$ is $14.9 \mathrm{kPa}$ for SC+SC geometry and $3.4 \mathrm{kPa}$ for $\mathrm{GC}+\mathrm{GC}$. Also, for smooth geometry, the average value of $\mathrm{G}_{\mathrm{LVR}}^{\prime}$ is $32 \%$ lower compared to the grooved geometry. Thus, it is possible to assume that apparent wall slip has an effect on the accuracy

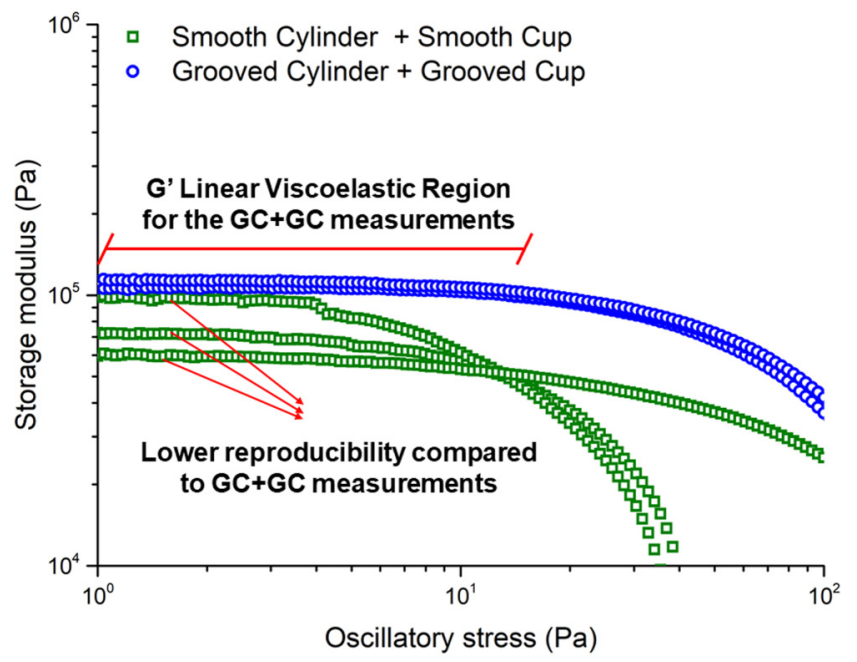

FIG. 8. Storage modulus as a function of oscillatory stress for $3.0 \mathrm{wt} \%$ systems measured with $\mathrm{SC}+\mathrm{SC}$ (squares) and GC + GC (circles) geometry configurations.

of the $\mathrm{G}^{\prime}$ measurement. Yoshimura and Prud'homme [53], considering a Kelvin-Voigt material constitutive relationship, also concluded that the presence of slip makes the fluid (oil-in-water emulsion in that investigation) appeared to be less elastic than it really is.

\section{Creep tests}

An alternative method for measuring the yield stress of a waxy gel is obtaining a bifurcation behavior by performing creep tests. These tests consist of applying a constant stress to the system and evaluating the strain response of the gel as a function of time. If several creep tests are performed at different stress levels for a sufficient amount of time, then the yield stress can be determined as the stress value above which the flow is observed. A period of time ranging from 2 to $10 \mathrm{~min}$ is usually employed for each test [54]. In principle, creep tests would produce more reliable measurements of yield stress in the flow assurance context. This is so because when a pipeline is shutdown and becomes blocked with a waxy gel, then, in the restart process, the pump is turned on and there is a sudden increase in stress in the gel, which is transmitted to the entire line. The disadvantage of the creep test method is that obtaining a single yield stress value for the waxy gel is time-consuming, because several experiments are needed. In this sense, oscillatory experiments are a more suitable option for an extensive investigation.

In the present investigation, creep experiments were performed with $\mathrm{SC}+\mathrm{SC}$ and $\mathrm{GC}+\mathrm{GC}$ geometries for the $3.0 \mathrm{wt}$ \% system, according to the protocol described in Sec. II B. These geometries give rise to the lowest and maximum values of yield stress, respectively, for both compositions assessed with oscillatory tests (Table III). Thus, the values obtained with oscillatory measurements were used as a guide to probe stress levels corresponding to the yield stress determined by creep experiments.

The series of creep tests begin with low stresses (lower than yield stress) applied to the sample; thus, the system behaves similarly to a viscoelastic solid. The stress is 
increased, and several creep curves are obtained. The yield stress was defined as the first value of stress that causes a marked increase in the geometry angular speed, as in creep experiments the gel breakage can be associated with a sudden increase in the rotor angular velocity [32]. The results are shown in Fig. 9.

It can be seen in Fig. 9(a) that the yield stress obtained with the SC+SC geometry is in the range of $60-65 \mathrm{~Pa}$. This is so because when smaller stress values are applied to the material in a Couette geometry with smooth surfaces, the resulting rotation velocity is negligible up to critical deformation beyond which the material moves influenced by the apparent wall slip. For stress levels of up to $60 \mathrm{~Pa}$, the gelled structure is maintained virtually intact, which is inferred from the negligible angular velocity (less than $10^{-3} \mathrm{rad} / \mathrm{s}$ ) during the test. As the experiment is performed at $65 \mathrm{~Pa}$, an acute angular response is captured, first at $0.6 \mathrm{~s}$, as the angular velocity increases from $\sim 10^{-3}$ to $3.2 \mathrm{rad} / \mathrm{s}$, and then at $28 \mathrm{~s}$ with an increase from $\sim 3.2$ to $85 \mathrm{rad} / \mathrm{s}$. This leads to the interpretation that the waxy-gelled structure is completely disrupted at $28 \mathrm{~s}$, as the inner cylinder of the SC + SC geometry is able to move with low resistance. The most probable
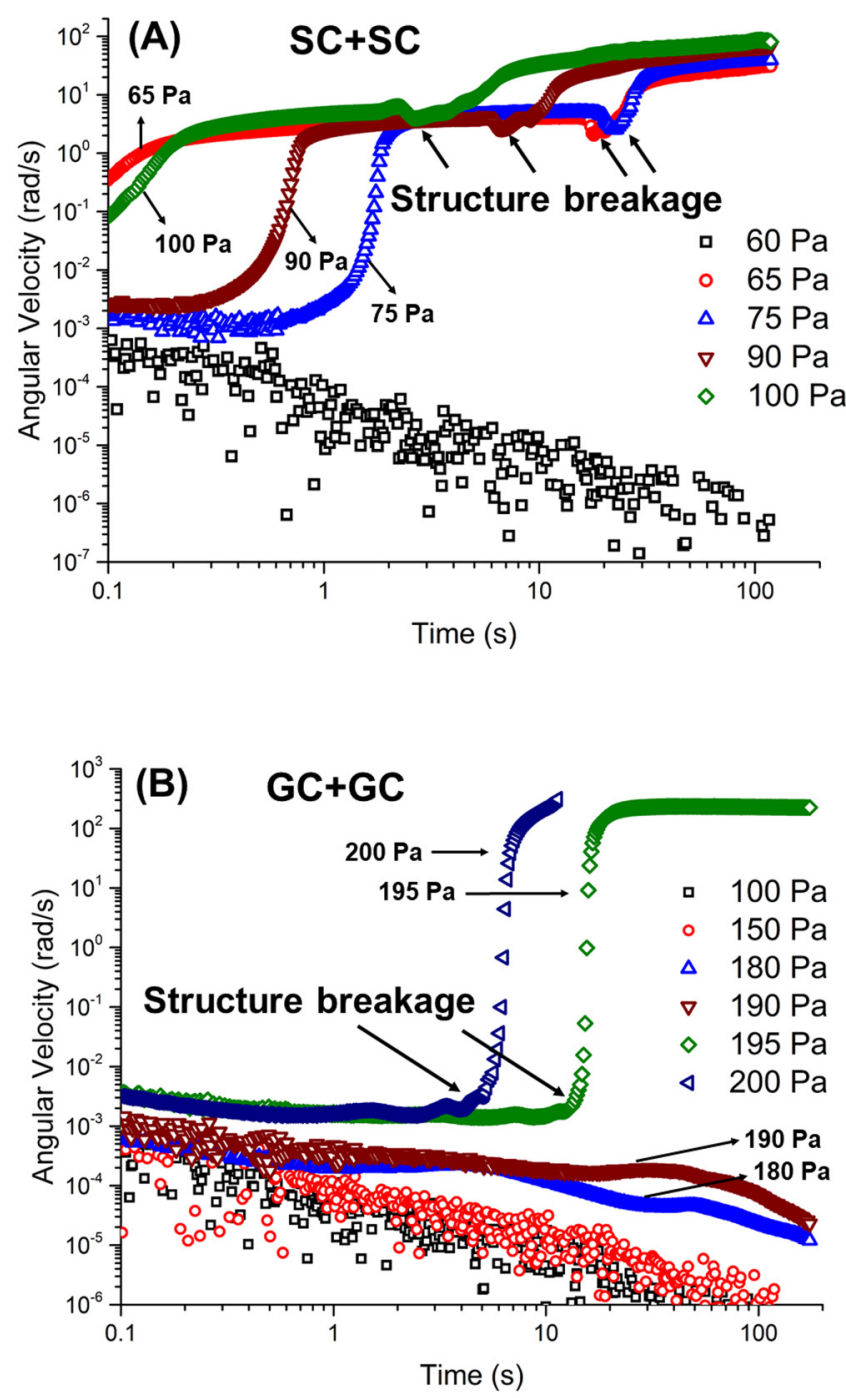

FIG. 9. Creep tests for model oils $3.0 \mathrm{wt}$ \% at all-smooth $\mathrm{SC}+\mathrm{SC}$ (a) and all-grooved GC + GC geometry (b). points of structure breakage for the applied stresses of 65,75 , 90, and $100 \mathrm{~Pa}$ are indicated by black arrows in Fig. 9(a). The first sharp increase in angular velocity for the stress level of $65 \mathrm{~Pa}$ suggests that immediately after applying the stress, the waxy gel slides in the geometry walls in the first $2 \mathrm{~s}$. The same behavior is observed for stress levels higher than $65 \mathrm{~Pa}$, although the time to reach the first angular velocity plateau and the period of gel breakage is shortened, except for the stress of $75 \mathrm{~Pa}$, where the breakage time is close to breakage time for the stress level of $65 \mathrm{~Pa}$. It is also interesting to note that near the breakage point there is a kink in the curve, which is much less pronounced for the GC+ GC geometry [Fig. 9(b)].

Figure 9(b) shows creep tests with the all-grooved GC + GC geometry. It is possible to observe that stress levels of up to $190 \mathrm{~Pa}$ result in a negligible angular velocity (less than $10^{-3} \mathrm{rad} / \mathrm{s}$ ), indicating that the yielding of this sample occurs at higher stresses. When the test is performed with $195 \mathrm{~Pa}$, the angular velocity increases about five orders of magnitude to more than $200 \mathrm{rad} / \mathrm{s}$ after $14.9 \mathrm{~s}$. For $200 \mathrm{~Pa}$, this response is shortened to $5.8 \mathrm{~s}$, with angular velocity reaching the equipment speed limit. Thus, according to the criteria employed for the yield stress in creep tests, the value is between 190 and $195 \mathrm{~Pa}$, indicating that an average decrease of $68 \%$ is obtained if the measurements are performed with $\mathrm{SC}+\mathrm{SC}$. It is important to note that the behavior observed between 190 and $195 \mathrm{~Pa}$ is likely to be associated to yielding and not to sample fracture because the limiting angular velocity of the equipment is not achieved in this stress range, so the geometry cannot spin freely as it would occur in the case of sample fracture. However, a definite conclusion on whether yielding or sample fracture occurs can only be drawn with an experimental investigation of the velocity profile in the sample.

When comparing Figs. 9(a) and 9(b), there is a difference not only in the yield stress value but also in the behavior of the curves. For $\mathrm{GC}+\mathrm{GC}$, there is only one unequivocal sharp increase in angular velocity when the stress level is either 195 or $200 \mathrm{~Pa}$, as indicated by a black arrow. This is the point of gel breakage when all-grooved surfaces are used. Thus, it seems reasonable to assume that the difference in the shape of the angular vs time curve is also due to apparent wall slip.

Comparing the yield stress values obtained from creep tests to that obtained from oscillatory tests, it is possible to note a significant difference. For the SC+SC geometry, creep tests provided a yield stress value between 60 and $65 \mathrm{~Pa}$, while the oscillatory tests provided a value of $40 \mathrm{~Pa}$. For the GC + GC geometry, the yield stress value obtained from creep tests is between 190 and $195 \mathrm{~Pa}$ in contrast to $259 \mathrm{~Pa}$ obtained from oscillatory tests. These differences can be attributed not only to apparent wall slip effects, but also to the time-dependency of the measurements for different tests performed $[10,46]$. The two different methods could provide more similar results for comparable time scales of measurement. In this regard, a series of creep tests can provide a time-independent yield stress value for sufficiently long tests, while oscillatory tests can require sufficiently high frequencies $[10,46]$. For comparison, oscillatory tests with 
$3.0 \mathrm{wt}$ \% samples were run in triplicate with the grooved Couette geometry. The procedure employed was the same as described in Sec. II B for oscillatory measurements, except for the frequency, which were set to either 0.1 or $4 \mathrm{~Hz}$. For $0.1 \mathrm{~Hz}$, the yield stress was calculated as $312 \pm 21 \mathrm{~Pa}$. For $4 \mathrm{~Hz}$, the yield stress obtained was $242 \pm 28 \mathrm{~Pa}$. The values of yield stress for $1 \mathrm{~Hz}$ reported above $(259 \pm 26 \mathrm{~Pa})$ and $4 \mathrm{~Hz}(242 \pm 28 \mathrm{~Pa})$ are statistically similar. These results indicate that for sufficiently high frequencies, the yield stress does not depend on the frequency, and consequently, the time-dependency of the measurements is removed $[10,46]$.

\section{Flow curves}

Flow curves of waxy gels were obtained from steady-state rheological experiments performed with the smooth $(\mathrm{SC}+\mathrm{SC})$ and grooved Couette $(\mathrm{GC}+\mathrm{GC})$ geometries, according to the protocol described in Sec. II B. If apparent wall slip is present, then bulk rheological properties are not accurately measured. Thus, for samples prone to slip, steady-state rheological experiments also require a judicious preparation. The first experimental concern is related to the equilibration time, as it must be ensured that each point in the flow curve corresponds to a particular steady state. In Fig. 10, it is shown that reproducible results are obtained for the flow curve of the $7.5 \mathrm{wt}$ \% model oil at $4{ }^{\circ} \mathrm{C}$ during the logarithmic sweep of shear rate with GC + GC geometry.

The Taylor number $T a$, a dimensionless quantity that characterizes the importance of inertial forces relative to viscous force due to rotation of a fluid about an axis, was also calculated. $T a$ values higher than $\sim 3400$ indicate inertial instability in the Couette flow [55]. Nonetheless, the highest Taylor number obtained was 225 for the $3.0 \mathrm{wt}$ \% model oil with $\mathrm{SC}+\mathrm{SC}$ geometry at the shear rate of $10^{3} \mathrm{~s}^{-1}$. These results indicate that Taylor's vortices do not affect the measurements at the high shear rates assessed.

The flow curve obtained with both the $\mathrm{SC}+\mathrm{SC}$ and $\mathrm{GC}+\mathrm{GC}$ geometries for the $3.0 \mathrm{wt}$. \% system is plotted in terms of viscosity vs shear rate and stress vs shear rate in

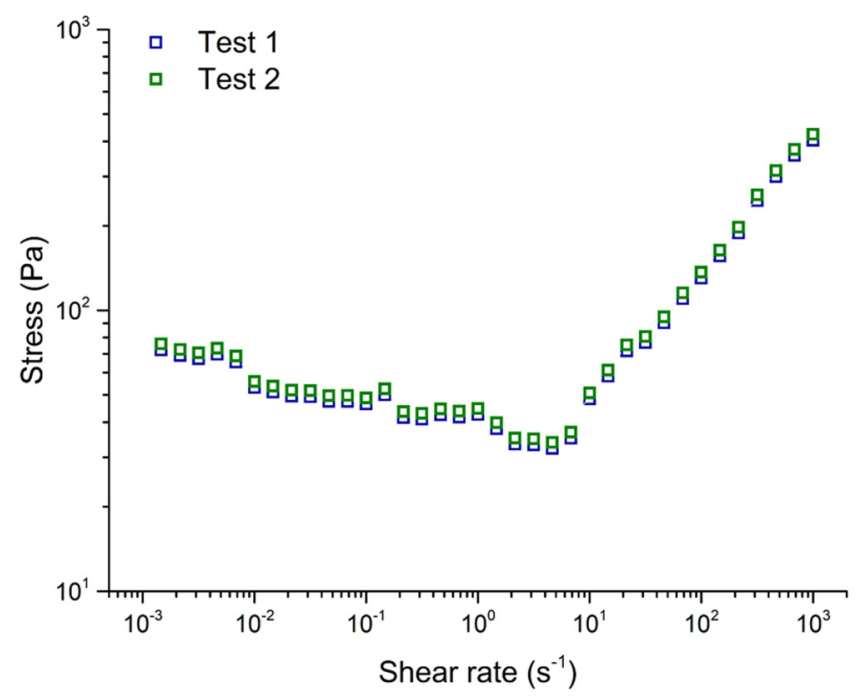

FIG. 10. Reproducibility of the flow curve obtained for a model oil 7.5 wt. $\%$ at $4{ }^{\circ} \mathrm{C}$ with $\mathrm{GC}+\mathrm{GC}$ geometry.
Fig. 11. As it can be observed, the reproducibility is clearly enhanced with GC + GC. Sánchez et al. [56] investigated the influence of the preparation method on apparent wall slip of model emulsions with smooth and rough surface geometries and obtained similar results in terms of reproducibility. The authors noticed that the region in which apparent wall slip is more pronounced corresponds to a region of low reproducibility in the values of the flow curve obtained with smooth surfaces. On the contrary, the flow curves obtained by using geometries with rough surfaces were highly reproducible [56].

In Fig. 11, above shear rates of $\sim 1.0 \mathrm{~s}^{-1}$, the curves for both geometries are nearly coincident. However, much lower stress values are obtained with the SC + SC geometry for shear rates between 0.1 and $1.0 \mathrm{~s}^{-1}$ [Fig. 11(b)], reflecting in lower viscosity values. This decrease in the measured viscosity is likely to be caused by apparent wall slip, as discussed in the literature [14-20,53,57]. For example, Buscall et al. [15] observed for concentrated colloidal dispersions that apparent wall slip is eliminated at sufficiently high shear stresses. Bertola et al. [58] came up with the same conclusion for a
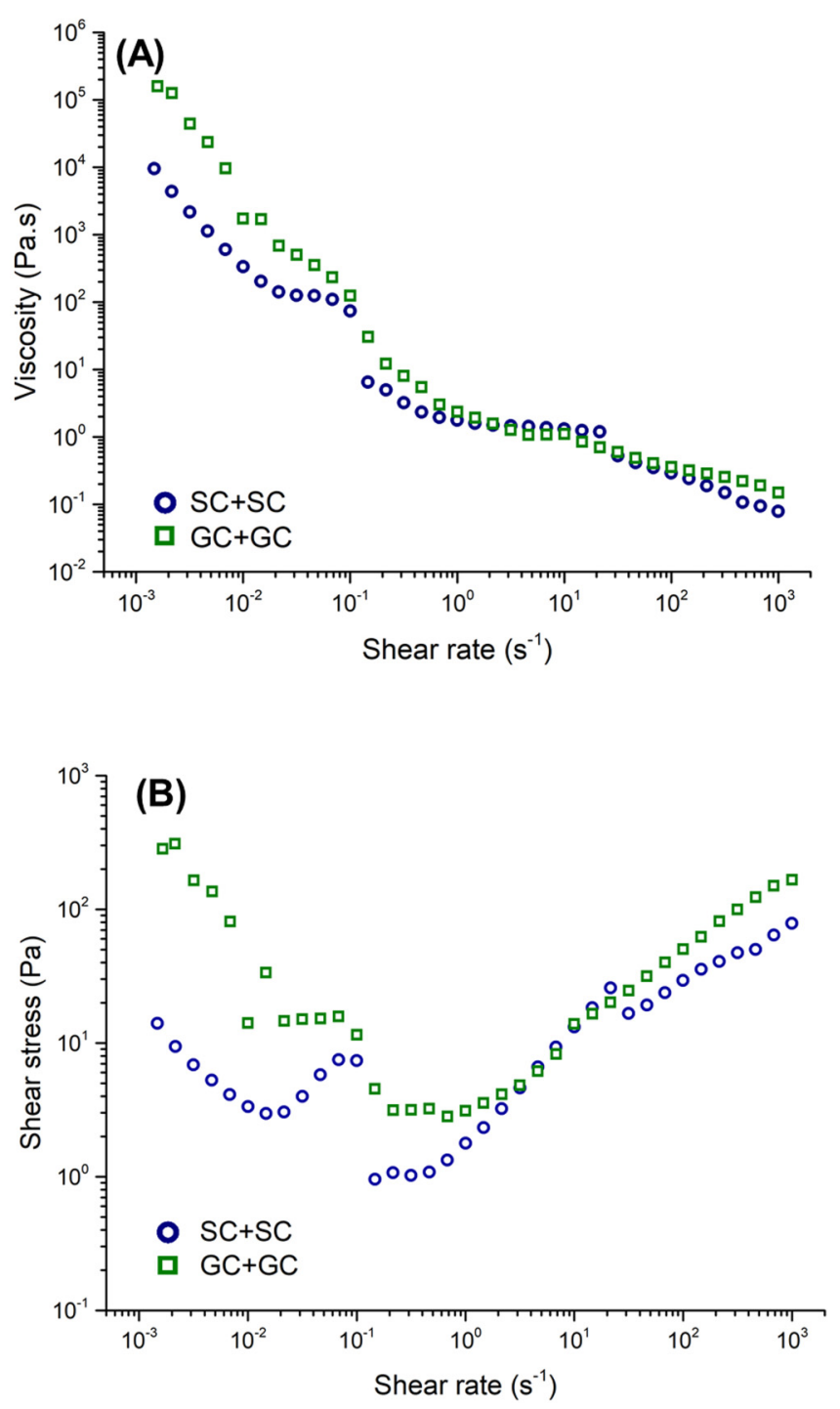

FIG. 11. Representative curves for model oil $3.0 \mathrm{wt}$ \%: viscosity (a) and shear stress (b). 
shaving cream. Below shear rates of $\sim 0.1 \mathrm{~s}^{-1}$, the results are less reproducible and a non-monotonic region in the flow curve can be identified, indicating the presence of shear banding effects in this region. Shear banding is a flow instability observed for materials presenting two yield stresses, a static and a dynamic yield stress, which occurs in the stress range in between the two yield stresses, thus affecting rheometric measurements [59-63]. The static yield stress can be defined as the limiting stress above which the material flows from rest, while the dynamic yield stress can be defined as the minimum stress required to keep the material flowing. In that regard, because of shear banding instability, it becomes difficult to estimate the static yield stress from the flow curve for comparison with the previously employed techniques, but the dynamic yield stress can be obtained by extrapolating the nearly constant stress in the range between 0.1 and $1.0 \mathrm{~s}^{-1}$ to the zero shear rate. By following this procedure, it can be seen in Fig. 11(b) that the dynamic yield stress can be estimated around $2.8 \mathrm{~Pa}$ for the $3.0 \mathrm{wt}$ \% system.

Figure 12 shows the flow curve for the $7.5 \mathrm{wt} . \%$ system at $4{ }^{\circ} \mathrm{C}$ also plotted in terms of viscosity vs shear rate and
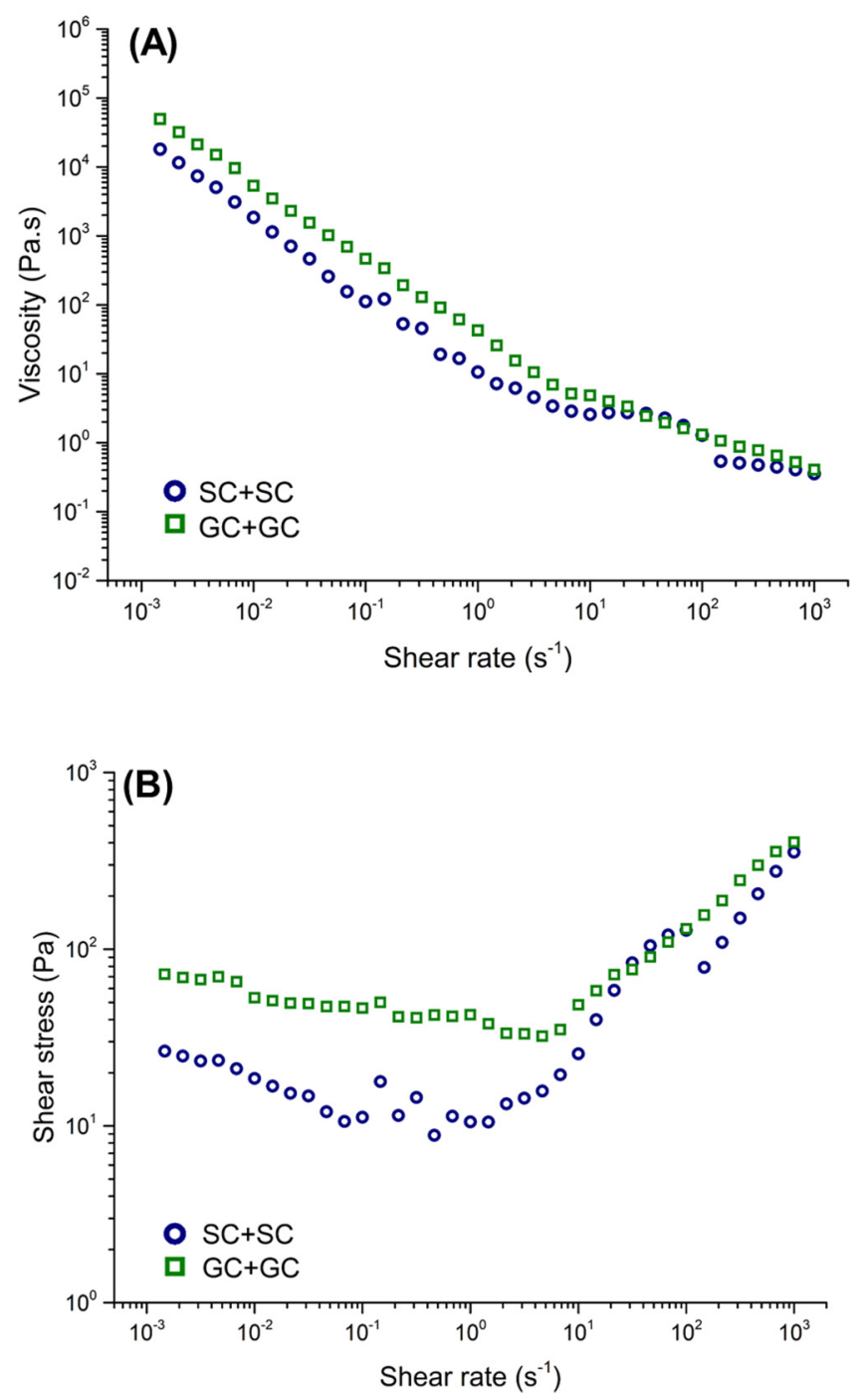

FIG. 12. Representative curves for model oil $7.5 \mathrm{wt}$ \%: viscosity (a) and shear stress (b). stress vs shear rate. The same rationale applies for the $7.5 \mathrm{wt} . \%$ system, although the convergence of the curves is shifted to higher values of shear rate (around $20 \mathrm{~s}^{-1}$ ). A possible explanation for this difference is the stiffer structure developed by a system that contains more waxy components in its composition. For the $7.5 \mathrm{wt} . \%$ system, the dynamic yield stress can be estimated as approximately $31 \mathrm{~Pa}$ if the minimum stress of the $\mathrm{GC}+\mathrm{GC}$ curve is extrapolated to the zero shear rate. For both 3.0 and $7.5 \mathrm{wt}$ \% systems, the flow curves are nearly coincident for sufficiently high shear rate values, indicating no apparent wall slip in this range. In the particular case of the $7.5 \mathrm{wt}$ \% system, an abrupt decay in viscosity measurements is observed at a shear rate above $100 \mathrm{~s}^{-1}$ only for the SC + SC geometry. A possible explanation for this behavior is related to adhesive failure (or true wall slip) between the sample and the geometry surfaces.

At last, as apparent wall slip causes a decrease in the measured viscosity, it can be quantified as the relative difference between the areas under the curves obtained using geometries with smooth and grooved surfaces [56]. For the $3.0 \mathrm{wt} \%$ system, the areas were calculated as $203.2 \mathrm{~Pa}$ $(\mathrm{SC}+\mathrm{SC})$ and $266.1 \mathrm{~Pa}(\mathrm{GC}+\mathrm{GC})$. Thus, a decrease of $24 \%$ can be computed. For $7.5 \mathrm{wt} \%$, the areas were $672.4 \mathrm{~Pa}(\mathrm{SC}+\mathrm{SC})$ and $969 \mathrm{~Pa}(\mathrm{GC}+\mathrm{GC})$, and a decrease of $31 \%$ is calculated. These results indicate that the viscosity of waxy gels is more affected by apparent wall slip for higher concentrations, at least for the systems investigated in this concentration range.

\section{Analysis of the apparent slip velocity}

The experimental data gathered in steady-state rheological experiments were used to estimate the apparent slip velocity. In the concentric cylinders geometry, the shear stress $\sigma$ applied to the sample is homogeneous. For cylinders with a radius ratio $\kappa$ between 0.9 and $0.99, \sigma$ can be described as [20]

$$
\sigma=\frac{T}{4 \pi L R^{2}}\left(\frac{\kappa^{2}+1}{\kappa^{2}}\right)
$$

where $R$ is the radius of the outer cylinder, $T$ is the applied torque, and $L$ is the length of the inner cylinder. The resulting apparent shear rate $\dot{\gamma}_{a p}$ for this geometry can be given by

$$
\dot{\gamma}_{a p}=\omega\left(\frac{1+\kappa^{2}}{1-\kappa^{2}}\right)
$$

where $\omega$ is the angular velocity, as detailed in Fig. 13.

As the shear stress is homogeneous within this geometry, and assuming that the apparent slip velocity $v_{\text {slip }}$ is a function of the shear stress only [19], it is possible to write from Eq. (3) and Fig. 13 that

$$
\dot{\gamma}_{a p}=\left(\frac{v_{\text {slip }}}{R}+\omega_{\mathrm{ef}}+\frac{v_{\text {slip }}}{\kappa R}\right)\left(\frac{1+\kappa^{2}}{1-\kappa^{2}}\right),
$$

where $\omega_{\mathrm{ef}}$ is the effective angular velocity perceived by the sample. 


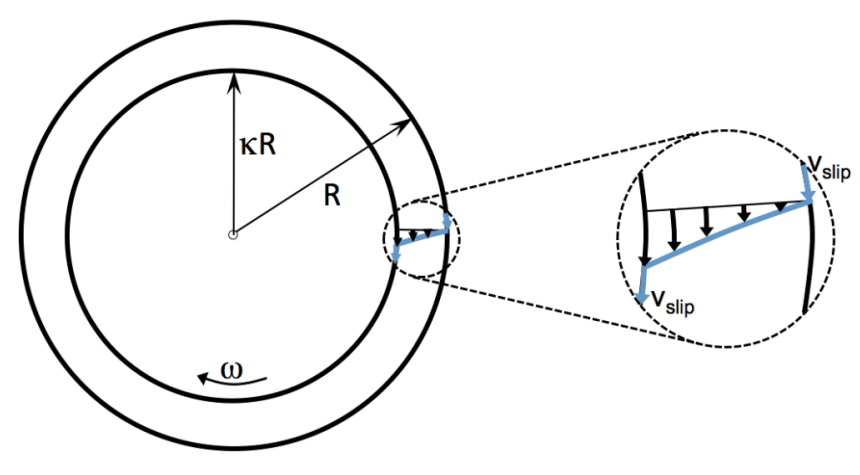

FIG. 13. Schematic drawing of the smooth concentric cylinders geometry with a sample presenting an apparent slip velocity $v_{\text {slip }}$ at both the inner and outer walls, as depicted in detail.

Rearranging Eq. (4), $\dot{\gamma}_{\text {ap }}$ becomes

$$
\dot{\gamma}_{\text {ap }}=\dot{\gamma}_{\text {ef }}+v_{\text {slip }}\left[\frac{1}{R(1-\kappa)}\right]\left[\frac{1+\kappa^{2}}{\kappa}\right] \text {, }
$$

which is similar to the equation for very narrow gaps $(\kappa>0.99)$ discussed by Cloitre and Bonnecaze [19] but extended for $\kappa>0.9$.

It can be noted in Eq. (5) that for two sets of concentric cylinders presenting the same $R$ and $\kappa$, but significantly different surface roughness, $v_{\text {slip }}(\sigma)$ can be determined by measuring $\dot{\gamma}_{\text {ap }}(\sigma)$ with the smooth cylinders and $\dot{\gamma}_{\text {ef }}(\sigma)$ with the roughened cylinders. It is worth mentioning that this procedure relies on the assumptions that (i) $v_{\text {slip }}=v_{\text {slip }}(\sigma)$, and (ii) apparent wall slip effects are suppressed in the measurements with the roughened cylinders. Therefore, it can be written as

$$
v_{\text {slip }}(\sigma)=\left[\dot{\gamma}_{\text {smooth }}(\sigma)-\dot{\gamma}_{\text {rough }}(\sigma)\right]\left[\frac{\kappa(1-\kappa)}{1+\kappa^{2}}\right] R
$$

From Eq. (6) and the results obtained with the smooth $(\mathrm{SC}+\mathrm{SC})$ and grooved Couette $(\mathrm{GC}+\mathrm{GC})$ geometries, it was possible to estimate the apparent slip velocity. These data are presented in Fig. 14. The dimensionless apparent slip velocity, i.e., $v_{\text {slip }} / v_{\text {slip }}^{*}$, is plotted as a function of the dimensionless shear stress, $\sigma / \sigma_{y}$. It can be seen in this figure that for the $3.0 \mathrm{wt} \%$ system, the slip velocity decreases as the dimensionless shear stress increases and approaches zero, i.e., no apparent wall slip, as the dimensionless shear stress approaches 1.5 . For the $7.5 \mathrm{wt} \%$ system, the slip velocity slightly decreases and achieves a nearly constant value as the dimensionless shear stress approaches 2 . These results indicate that for low concentrated wax crystal suspensions, the slip velocity depends on both (i) the ratio between the shear stress and the dynamic yield stress and (ii) concentration. As the concentration of wax crystals increases, the slip velocity increases and approaches a constant relatively high value in the regime just above the yield stress, i.e., $1<\sigma / \sigma_{y}<2$. This finding suggests that for even higher concentrations of wax crystals, it would be possible to achieve a constant high value of slip velocity in this regime just above the yield stress, as reported by Meeker et al. [64,65] and discussed by Divoux et al. [66] for concentrated dispersions. It is

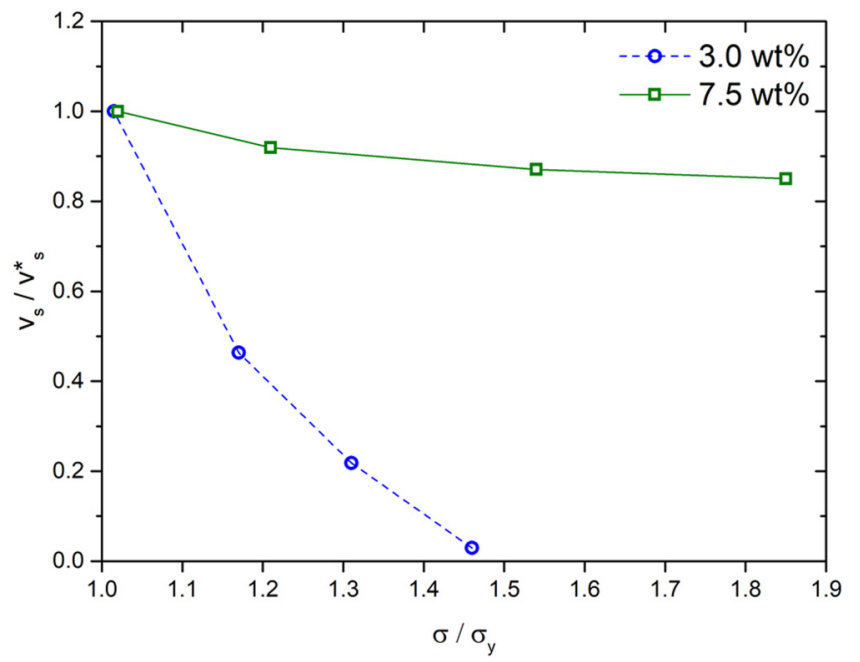

FIG. 14. Dimensionless apparent slip velocity for 3.0 and $7.5 \mathrm{wt} \%$ model oils as a function of dimensionless shear stress. For the model oil $3.0 \mathrm{wt}$. \%, $v_{\text {slip }}^{*}$ was set to $1.86 \mathrm{~mm} / \mathrm{s}$ and the yield stress to $2.8 \mathrm{~Pa}$. For the $7.5 \mathrm{wt}$. \%, these values were $15.1 \mathrm{~mm} / \mathrm{s}$ and $31 \mathrm{~Pa}$.

important to note that, in Sec. III C 1, it is found that apparent wall slip is not composition-dependent for oscillatory tests, while in this section it is shown that the slip velocity depends on concentration for steady-shear experiments. This opposite qualitative behavior is attributed to the different regimes investigated. In oscillatory tests, the data are discussed in the regime below the yield stress, while for steadyshear experiments the data are discussed in the regime just above the yield stress.

\section{Potential impact on pipeline transportation}

As discussed, the phenomenon of apparent wall slip is not restricted to simple shear flows employed in rheological measurements but can be observed in more general flows of waxy gels. Therefore, it is important for the oil industry to evaluate whether apparent wall slip can occur in the field and its potential impact on pipeline design and transportation. In particular, in the event of a shutdown of a pipeline carrying a waxy crude oil in a cold environment (e.g., a subsea pipeline), wax crystals can precipitate and lead to oil gelation. In this scenario, the pressure required to restart the flow in a pipeline is usually calculated based on bulk rheological properties of waxy gels with no apparent wall slip effects. If apparent wall slip occurs in the field, then the required restart pressure can be overpredicted.

For pipes commonly used in subsea operations, the surface roughness varies from 30 to $50 \mu \mathrm{m}$ [34]. According to Choate [35], values of $12 \mu \mathrm{m}$ can be obtained from a complete pigging operation on an internally bare steel pipe, although many consecutive brush and scraper pigs would be run. Coated surfaces are less prone to experience contamination build-up over time. For an internally coated pipeline, an ideal roughness of $5 \mu \mathrm{m}$ could be possibly obtained [35,67]. According to the data shown in Table II, it is possible to conclude that in terms of surface roughness, the smooth geometries employed in the rheometer do not represent the internal walls of pipelines commonly used in the oil industry. 
Even internally coated pipes have a surface roughness approximately 25 times larger than the surface of smooth geometries. However, the surface of grooved geometries can represent a typical oil pipeline. For example, considering the $\mathrm{R}_{\mathrm{a}}$ of $87 \mu \mathrm{m}$ for the grooved parallel plate, this value is comparable to the absolute roughness of typical pipes used to transport oil in subsea operations $(30-50 \mu \mathrm{m})$ [34]. It is worth mentioning that the surface roughness in the pipe wall tends to increase with time due to constant material incrustations and pigging operations [67].

Considering that shear rates in the pipe flow range from 1 to $10^{3} \mathrm{~s}^{-1}$ [68]:

(i) For the $3.0 \mathrm{wt} \% \%$ model oil, the surface roughness of the smooth and grooved geometries do not play a major role in shear rates higher than $1 \mathrm{~s}^{-1}$ (see Fig. 11). In this case, apparent wall slip manifests in lower shear rates than the range for the pipe flow; therefore, it would not be expected in the field for this system.

(ii) For the $7.5 \mathrm{wt} . \%$ model oil, the surface roughness clearly affects the flow behavior of a gelled material in the range that includes 1 to $\sim 20 \mathrm{~s}^{-1}$ (see Fig. 12). Thus, apparent wall slip can occur in a pipe clogged with this material if the surface roughness is sufficiently low. This result highlights the importance of employing smooth internal walls for the transport of crude oils with high wax content. For example, in the case of $7.5 \mathrm{wt}$. \% model oils, the measured yield stress decreases from $2700 \pm 252$ to $488 \pm 102 \mathrm{~Pa}$ (Table III); thus, a significant effect on the calculated restart pressure and pumping capacity can be expected. Moreover, considering the behavior observed in Sec. III C 4 for apparent slip velocities, one possible strategy to minimize pumping costs would be to operate a pipeline in the regime just above the yield stress by increasing wax crystals concentration to maximize apparent slip effects in this regime.

The flow characteristics of crude oils in pipes are also affected by the surface roughness as it creates unfavorable pressure and energy losses due to friction. The roughness reduces the pipe flow rate and increases costs thereby [67]. In a regular pumping operation, the throughput of a pipeline near its capacity is limited by a maximum allowable pressure drop at the compressor station. Industry has discovered the benefits of coated pipes for improving the flow performance by lowering the relative roughness and the friction factor values. By decreasing the pipe's internal surface roughness, higher throughput can be obtained without increasing the pressure drop [34]. In the case of a pipe clogged with wax, as roughness increase generally enhances adhesion [69], it is reasonable to expect for a given pipe diameter a lower pressure drop demand at restart flow operations on smoother surfaces. In other words, a lower surface roughness leads to an effective and efficient pipeline.

\section{CONCLUSION}

In this investigation, it is demonstrated by several rheological experiments that apparent wall slip has a considerable impact on the flow behavior of waxy gels. Measurements of rheological properties are affected by the phenomenon when smooth surfaces are present. The size of the wax particles relative to the surface roughness is a key contributor to the extent of apparent wall slip. It also becomes clear that the trade between a smooth to a grooved moving surface mitigates but do not eliminate apparent wall slip.

From oscillatory rheological measurements, a decrease of $\sim 80 \%$ in yield stress was calculated for different system compositions. Creep tests also indicated an average decrease of $68 \%$ if measurements are made with smooth Couette geometry. There is also evidence that apparent wall slip is more pronounced when the moving part of the geometry is smooth. When all-grooved geometries are used, the reproducibility of the yield stress measurements is improved.

Apparent wall slip has also a clear influence in the storage modulus since this property is underestimated when measured by geometries with smooth parts. For geometries with a smooth part, the property was captured in a log-log plot even when the system is far from the linear viscoelastic region, which was not the case for the all-grooved geometries. Thus, the storage modulus measurement may provide an indirect evidence of apparent wall slip in this case.

Flow curves also exhibited much lower stress values when smooth Couette geometry was employed, reflecting in lower values of the measured viscosity. This is likely to be caused by apparent wall slip. For the all-grooved geometry, under a steady imposed shear rate, the inhibition of apparent slip effects resulted in a higher stress required to achieve a steady flow. Apparent slip velocities were calculated based on steady-state rheological experiments for the regime just above the yield stress, i.e., $1<\sigma / \sigma_{y}<2$. It is found that for these low concentrated waxy suspensions, the apparent slip velocity increases with concentration and decreases with the ratio between the shear stress and dynamic yield stress.

This work calls the attention for the severity of apparent wall slip effects on rheological measurements of waxy gels. It was observed that the yield stress measurements strongly depend on surface roughness employed. Thus, in order to obtain accurate rheological data for systems prone to present apparent wall slip, the use of grooved surfaces for both moving and stationary parts during measurements is highly recommended. Future experimental and numerical works investigating the flow kinematics inside profiled geometries can shed light into the best geometry choice for each kind of material. The potential impact of these results on pipeline transportation is discussed, and the importance of employing smooth internal walls for the transport of crude oils with high wax content is highlighted.

\section{ACKNOWLEDGMENTS}

The authors thank Petrobras and CNPq (Conselho Nacional de Pesquisa e Desenvolvimento) for supporting this work.

\section{REFERENCES}

[1] Davenport, T. C., and R. S. H. Somper, "The yield value and breakdown of crude oil gels,” J. Inst. Pet. 57, 86-105 (1971). 
[2] Petrellis, N. C., and R. W. Flumerfelt, "Rheological behavior of shear degradable oils: Kinetic and equilibrium properties," Can. J. Chem. Eng. 51(3), 291-301 (1973).

[3] Smith, P. B., and R. M. J. Ramsden, "The prediction of oil gelation in submarine pipelines and the pressure required for restarting flow," Eur. Offshore Pet. Conf. 56(3), 283-290 (1978).

[4] Venkatesan, R., N. R. Nagarajan, K. Paso, Y. Yi, A. M. Sastry, and H. S. Fogler, "The strength of paraffin gels formed under static and flow conditions," Chem. Eng. Sci. 60, 3587-3598 (2005).

[5] Aiyejina, A., D. P. Chakrabarti, A. Pilgrim, and M. K. S. Sastry, "Wax formation in oil pipelines: A critical review," Int. J. Multiph. Flow 37(7), 671-694 (2011).

[6] Zhao, Y., L. Kumar, K. Paso, J. Safieva, M. Z. B. Sariman, and J. Sjöblom, "Gelation behavior of model wax-oil and crude oil systems and yield stress model development," Energy Fuels 26(10), 6323-6331 (2012).

[7] Cabanillas, J. P., A. T. Leiroz, and L. F. A. Azevedo, "Wax deposition in the presence of suspended crystals," Energy Fuels 30(1), 1-11 (2016).

[8] Wardhaugh, L. T., and D. V. Boger, "Measurement of the unique flow properties of waxy crude oils," Chem. Eng. Res. Des. 65, 74-83 (1987).

[9] Wardhaugh, L. T., and D. V. Boger, "Flow characteristics of waxy crude oils: Application to pipeline design," AIChE J. 37(6), 871-885 (1991).

[10] Wardhaugh, L. T., and D. V. Boger, "The measurement and description of the yielding behavior of waxy crude oil," J. Rheol. 35(6), 1121-1156 (1991).

[11] Rønningsen, H. P., "Rheological behaviour of gelled, waxy North Sea crude oils,” J. Pet. Sci. Eng. 7(3-4), 177-213 (1992).

[12] Marchesini, F. H., A. A. Alicke, P. R. De Souza Mendes, and C. M. Ziglio, "Rheological characterization of waxy crude oils: Sample preparation,” Energy Fuels 26(5), 2566-2577 (2012).

[13] Davidson, M. R., Q. D. Nguyen, C. Chang, and H. P. Rønningsen, “A model for restart of a pipeline with compressible gelled waxy crude oil," J. Nonnewton. Fluid Mech. 123(2-3), 269-280 (2004).

[14] Barnes, H. A., "A review of slip (wall depletion) of polymer solutions, emusions and particle suspensions in viscometers: Its cause, character, and cure," J. Nonnewton. Fluid Mech. 56, 221-251 (1995).

[15] Buscall, R., J. I. Mcgowan, and A. J. Mortonjones, "The rheology of concentrated dispersions of weakly attracting colloidal particles with and without wall slip,” J. Rheol. 37, 621-641 (1993).

[16] Russel, W. B., and M. C. Grant, "Distinguishing between dynamic yielding and wall slip in a weakly flocculated colloidal dispersion," Colloids Surf. 161(2), 271-282 (2000).

[17] Yoshimura, A., and R. K. Prud'homme, "Wall slip corrections for couette and parallel disk viscometers wall slip corrections for couette and parallel disk viscometers," J. Rheol. 32, 53-67 (1988).

[18] Walls, H. J., S. B. Caines, A. M. Sanchez, and S. A. Khan, "Yield stress and wall slip phenomena in colloidal silica gels," J. Rheol. 47(4), 847-868 (2003).

[19] Cloitre, M., and R. T. Bonnecaze, "A review on wall slip in high solid dispersions," Rheol. Acta 56(3), 283-305 (2017).

[20] Marchesini, F. H., M. F. Naccache, A. Abdu, A. A. Alicke, and P. R. de Souza Mendes, "Rheological characterization of yield-stress materials: Flow pattern and apparent wall slip," Appl. Rheol. 25(5), 53883 (2015).

[21] Carotenuto, C., A. Vananroye, J. Vermant, and M. Minale, "Predicting the apparent wall slip when using roughened geometries: A porous medium approach,” J. Rheol. 59(5), 1131-1149 (2015).

[22] Paduano, L. P., T. Schweizer, C. Carotenuto, J. Vermant, and M. Minale, "Rough geometries with viscoelastic boger fluids:
Predicting the apparent wall slip with a porous medium approach," J. Rheol. 63(4), 569-582 (2019).

[23] Nguyen, Q. D., and D. V. Boger, "Yield stress measurement for concentrated suspensions," J. Rheol. 27(4), 321-349 (1983).

[24] Nguyen, Q. D., and D. V. Boger, "Direct yield stress measurement with the vane method," J. Rheol. 29(3), 335-347 (1985).

[25] De Souza Mendes, P. R., A. A. Alicke, and R. L. Thompson, "Parallel-plate geometry correction for transient rheometric experiments," Appl. Rheol. 24(5), 52721 (2014).

[26] Bikos, D. A., and T. G. Mason, "Customizable tool geometries by additive manufacturing for mechanical rheometry of soft matter," J. Rheol. 60(6), 1257-1267 (2016).

[27] Owens, C. E., A. J. Hart, and G. H. McKinley, "Improved rheometry of yield stress fluids using bespoke fractal 3D printed vanes," J. Rheol. 64(3), 643-662 (2020).

[28] Dimitriou, C. J., G. H. McKinley, and R. Venkatesan, "Rheo-PIV analysis of the yielding and flow of model waxy crude oils," Energy Fuels 25(7), 3040-3052 (2011).

[29] Speight, J. G., The Chemistry and Technology of Petroleum, 5th ed. (CRC Press, Boca Raton, 2014).

[30] Marinho, T. O., C. N. Barbato, G. B. Freitas, C. Angela Duncke, D. O. Marcia Khalil, and M. Nele, "Interaction effects of predominantly linear and branched waxes on yield stress and elastic modulus of waxy oils," Energy Fuels 32(8), 8057-8068 (2018).

[31] Tinsley, J. F., J. P. Jahnke, H. D. Dettman, and R. K. Prud'home, "Waxy gels with asphaltenes 1: Characterization of precipitation, gelation, yield stress, and morphology," Energy Fuels 23(4), 2056-2064 (2009).

[32] Nguyen, Q. D., T. Akroyd, D. C. De Kee, and L. L. Zhu, "Yield stress measurements in suspensions: An inter-laboratory study," Korea-Australia Rheol. J. 18(1), 15-24 (2006).

[33] Whitehouse, D. J., Handbook of Surface Metrology (CRC Press, Boca Raton, 1994).

[34] Farshad, F. F., and H. H. Rieke, "Surface-roughness design values for modern pipes," SPE Drill. Complet. 21(3), 212-215 (2006).

[35] Choate, L. C., "Developing and advancing the state of the art technology of the in-situ internal cleaning and coating of oil and gas pipelines," presented at the CORROSION 2001 Symposium, Houston, TX, March 2001.

[36] Paiva, F. L., F. H. Marchesini, V. M. A. Calado, and A. P. Galliez, "Wax precipitation temperature measurements revisited: The role of the degree of sample confinement," Energy Fuels 31(7), 6862-6875 (2017).

[37] Chichakli, M., and F. W. Jessen, "Crystal morphology in hydrocarbon systems,” Ind. Eng. Chem. 59, 86-98 (1967).

[38] Ferris, S. W., and H. C. Cowles, "Crystal behavior of paraffin Wax," Ind. Eng. Chem. 37, 1054-1062 (1945).

[39] Singh, P., H. S. Fogler, and N. Nagarajan, "Prediction of the wax content of the incipient wax-oil gel in a pipeline: An application of the controlled-stress rheometer," J. Rheol. 43, 1437-1459 (1999).

[40] Dirand, M., V. Chevallier, E. Provost, M. Bouroukba, and D. Petitjean, "Multicomponent paraffin waxes and petroleum solid deposits structural and thermodynamic state," Fuel 77(12), 1253-1260 (1998).

[41] Létoffé, J. M., P. Claudy, M. V. Kok, M. Garcin, and J. L. Volle, "Crude oils: Characterization of waxes precipitated on cooling by d.s.c. and thermomicroscopy," Fuel 74(1), 810-817 (1995).

[42] Cazaux, G., L. Barre, and F. Brucy, "Waxy crude cold start: Assessment through gel structural properties," in SPE Annual Technical Conference and Exhibition, New Orleans, LA, 27-30 September 1998 (Society of Petroleum Engineers, Richardson, TX 1998), pp. 729-739.

[43] Barbato, C., B. Nogueira, M. Khalil, R. Fonseca, M. Gonçalves, J. C. Pinto, and M. Nele, "Contribution to a more reproductible 
method for measuring yield stress of waxy crude oil emulsions," Energy Fuels 28(1), 1717-1725 (2014).

[44] Sun, G., J. Zhang, and H. Li, "Structural behaviors of waxy crude oil emulsion gels," Energy Fuels 28(6), 3718-3729 (2014).

[45] Yang, F., C. Li, and D. Wang, "Studies on the structural characteristics of gelled waxy crude oils based on scaling model," Energy Fuels 27(3), 1307-1313 (2013).

[46] Chang, C., D. V. Boger, and Q. D. Nguyen, "The yielding of waxy crude oils," Ind. Eng. Chem. Res. 37(4), 1551-1559 (1998).

[47] Marinho, T. O., M. N. De Souza, C. N. Barbato, and M. C. Khalil de Oliveira, "Rheological and thermal behavior of water-waxy crude oil emulsions," in Offshore Technical Conference, Rio de Janeiro, Brazil, 27-29 October 2015 (Offshore Technology Conference, Houston, TX, 2015).

[48] Fernandes, R. R., D. E. V. Andrade, A. T. Franco, and C. O. R. Negrão, "Correlation between the gel-liquid transition stress and the storage modulus of an oil-based drilling fluid," J. Nonnewton. Fluid Mech. 231, 6-10 (2016).

[49] Lopes-da-Silva, J. A., and J. A. P. Coutinho, "Analysis of the isothermal structure development in waxy crude oils under quiescent conditions," Energy Fuels 21(6), 3612-3617 (2007).

[50] Mendes, R., G. Vinay, and P. Coussot, "Yield stress and minimum pressure for simulating the flow restart of a waxy crude oil pipeline," Energy Fuels 31(1), 395-407 (2017).

[51] Marinho, T. O., M. C. K. De Oliveira, and M. Nele, "Experimental investigation of the rheology and crystal morphology of model waxy oils under gelling conditions," Energy Fuels 33(10), 9604-9618 (2019).

[52] Visintin, R. F. G., T. P. Lockhart, R. Lapasin, and P. D'Antona, "Structure of waxy crude oil emulsion gels," J. Non-Newtonian Fluid Mech. 149(1-3), 34-39 (2008).

[53] Yoshimura, A. S., and R. K. Prud'homme, "Wall slip effects on dynamic oscillatory measurements," J. Rheol. 32(6), 575-584 (1988).

[54] Tadros, T. F., Rheology of Dispersions: Principles and Applications (Wiley VCH, Weinheim, Germany, 2010).

[55] Macosko, C. W., Rheology Principles, Measurements, and Applications (Wiley-VCH, Inc., Weinheim, Germany, 1994).
[56] Sánchez, M. C., C. Valencia, J. M. Franco, and C. Gallegos, "Wall slip phenomena in oil-in-water emulsions: Effect of some structural parameters," J. Colloid Interface Sci. 241(1), 226-232 (2001).

[57] Walter, B. L., J. P. Pelteret, J. Kaschta, D. W. Schubert, and P. Steinmann, "On the wall slip phenomenon of elastomers in oscillatory shear measurements using parallel-plate rotational rheometry: II. Influence of experimental conditions," Polym. Test. 61, 455-463 (2017).

[58] Bertola, V., F. Bertrand, H. Tabuteau, D. Bonn, and P. Coussot, "Wall slip and yielding in pasty materials," J. Rheol. 47(5), 1211-1226 (2003).

[59] Divoux, T., M. A. Fardin, S. Manneville, and S. Lerouge, "Shear banding of complex fluids," Annu. Rev. Fluid Mech. 48(1), 81-103 (2016).

[60] Hatzikiriakos, S. G., "Slip mechanisms in complex fluid flows," Soft Matter 11(40), 7851-7856 (2015).

[61] Dimitriou, C. J., and G. H. McKinley, "A comprehensive constitutive law for waxy crude oil: A thixotropic yield stress fluid," Soft Matter 10(35), 6619-6644 (2014).

[62] Barnes, H. A., "The yield stress—a review or 'panta Rei'—everything flows?,” J. Nonnewton. Fluid Mech. 81, 133-178 (1999).

[63] Møller, P. C. F., J. Mewis, and D. Bonn, "Yield stress and thixotropy: On the difficulty of measuring yield stresses in practice," Soft Matter 2(4), 274-283 (2006).

[64] Meeker, S. P., R. T. Bonnecaze, and M. Cloitre, "Slip and flow in soft particle pastes," Phys. Rev. Lett. 92(19), 198302-1-198302-4 (2004).

[65] Meeker, S. P., R. T. Bonnecaze, and M. Cloitre, "Slip and flow in pastes of soft particles," J. Rheol. 48(6), 1295-1320 (2004).

[66] Divoux, T., V. Lapeyre, V. Ravaine, and S. Manneville, "Wall slip across the jamming transition of soft thermoresponsive particles," Phys. Rev. E 92, 060301 (R) (2015).

[67] Farshad, F., H. Rieke, and J. Garber, "New developments in surface roughness measurements, characterization, and modeling fluid flow in pipe,” J. Pet. Sci. Eng. 29(2), 139-150 (2001).

[68] Chhabra, R. P., and J. F. Richardson, Non-Newtonian Flow and Applied Rheology, 2nd ed. (Elsevier, Oxford, UK, 2008).

[69] Lee, H. S., P. Singh, W. H. Thomason, and H. S. Fogler, "Waxy oil gel breaking mechanisms: Adhesive versus cohesive failure," Energy Fuels 22(1), 480-487 (2008). 